\title{
SUPPORTING THE COGNITIVE WORK OF INFORMATION ANALYSIS AND SYNTHESIS: A STUDY OF THE MILITARY INTELLIGENCE DOMAIN
}

\author{
A Thesis \\ Presented in Partial Fulfillment of the Requirements for \\ the Degree Master of Science in the \\ Graduate School of The Ohio State University \\ By
} Justin Brett Grossman, B.S. $* * * * *$

The Ohio State University 2007

Master's Examination Committee:

Dr. David D. Woods, Adviser

Dr. Emily S. Patterson

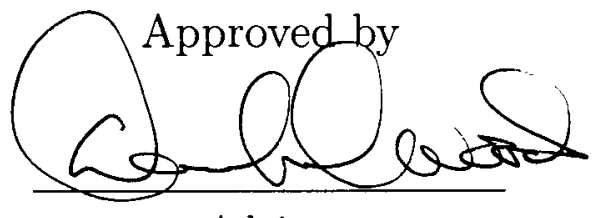

Adviser

Graduate Program in Industrial and Systems

Engineering 
(C) Copyright by

Justin Brett Grossman

2007 


\section{ABSTRACT}

Information Analysis and Synthesis (henceforth "IAS") is a type of cognitive work that plays a key role in many high-performance, complex, and mission-critical domains. These can range from tactical military intelligence to scientific or technological forecasting, business and financial intelligence to national strategic counterterrorism, and include areas as disparate as geopolitical policy analysis to computer network intrusion detection. The specific subject of this study is the military intelligence domain as one instantiation of IAS. Several innovative ethnographic and cognitive task analysis methods were used to observe team-based distributed work done by actual domain practitioners. The main investigative effort took the form of a scaled-world study, leveraging a real world tactical intelligence training exercise as a natural laboratory for investigating the contrasts between weaker and stronger IAS. Specifically, we examined the role of instructors in providing broadening checks to the team analytic process, and mapped the findings to an existing framework. 
To Emily and Turk, for keeping me mostly sane; and to my family, for giving me the foundation and support needed to succeed. 


\section{ACKNOWLEDGMENTS}

I would like to thank my advisor, Dr. David Woods for all the counsel and patience, and extraordinary insight and support. I would also like to thank my coadvisor Dr. Emily Patterson for the wonderful help and feedback along the way, and for all the observational opportunities. Stoney Trent, Martin Voshell, Josh Schoenwald, Jim Tittle, Cindy, Seth, and Matt (and of course Emily) made a great cohort and observer team in the desert, without which none of this would be possible. Bill Elm provided invaluable expertise and advice, and opportunity to turn this research into application.

I would also like to thank my family and friends for their patience and support throughout this process, and especially my beautiful and charming wife, Emily. (And patient, did I mention patient?) 


\section{VITA}

November 13, $1978 \ldots \ldots \ldots \ldots \ldots \ldots \ldots$. Born - Columbus, OH, USA

2000-2001 ........................ Technology Enhanced Learning \& Research designer, Ohio State University

$2001 \ldots \ldots \ldots \ldots \ldots \ldots \ldots \ldots \ldots \ldots \ldots \ldots$ Web Usability analyst Compuserve - AOL Web Properties

$2001 \ldots \ldots \ldots \ldots \ldots \ldots \ldots \ldots \ldots \ldots \ldots$.. . . Digital Information Design

2002-present ....................... Graduate Research Associate, Ohio State University

2004-present ...................... Junior Cognitive Systems Engineer, Cognitive Systems Engineering Center (CSEC), ManTech SMA

\section{PUBLICATIONS}

\section{Research Publications}

Elm, W. and Potter, S. and Tittle, J. and Woods, D. and Grossman, J. and Patterson, E. "Finding Decision Support Requirements for Effective Intelligence Analysis Tools". Proceedings Of The Human Factors And Ergonomics Society 49th Annual Meeting, 2005. Santa Monica, CA: Human Factors and Ergonomics Society.

\section{FIELDS OF STUDY}

Major Field: Industrial Systems Engineering 
Studies in:

Cognitive Systems Engineering

Human Factors Engineering 


\section{TABLE OF CONTENTS}

Page

Abstract .................... ii

Dedication . ......................... iii

Acknowledgments ..................... iv

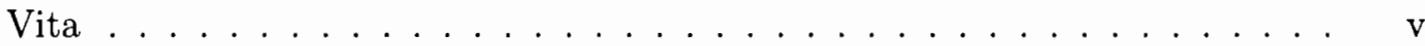

List of Tables ........................ ix

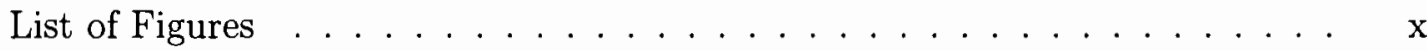

Chapters:

1. Introduction . . . . . . . . . . . . . . . . . . 1

1.1 Why a natural laboratory? . . . . . . . . . . . . 2

1.2 How does the functionalist perspective help one understand complex domains? . . . . . . . . . . . . . . . . 4

1.3 How does one understand the generic cognitive work of Information Analysis and Synthesis? . . . . . . . . . . . . 6

1.3.1 What is convergence? . . . . . . . . . . 7

1.3.2 How does rigor aid the determination of process quality? . . 8

1.4 What is the support function model of Information Analysis and Synthesis? . . . . . . . . . . . . . . . . . 10

1.5 How do instructor interventions serve as broadening checks? . . . . 12

1.6 Why is a field study of the military intelligence domain an interesting laboratory for studying IAS in general? . . . . . . . . . . . . 14

1.7 What are the general patterns in the multi-threaded work of IAS? . 16

1.7 .1 Tempo . . . . . . . . . . . . . . . 17 
1.7 .2 Escalation . . . . . . . . . . . . . . . . . . . . 17

1.7 .3 Coupling ....................... 17

1.7.4 Support Function Network as a tool for uncovering coupling 17

1.7 .5 Premature Narrowing . . . . . . . . . . . . . . . 17

1.7 .6 Reframing . . . . . . . . . . . . . . . 18

1.7 .7 Dilemmas . . . . . . . . . . . . . . . . . 18

1.7 .8 Over-simplifications . . . . . . . . . . . . 18

2. Methodology ... . . . . . . . . . . . . . . . . 19

2.1 Critique Study Method Paired With Elicitation . . . . . . . . . 19

2.2 "Northernstar" Scenario Scaled-World Study . . . . . . . . . . . 22

2.2 .1 Methodological Innovations . . . . . . . . . . . . . . . 25

2.2 .2 Prior-Participant Observers . . . . . . . . . . . . 25

2.2 .3 Distributed Observation Teams . . . . . . . . . . . . 26

2.2.4 Instructor Interventions as Probes into Broadening Checks . 27

3. Findings .............................. 29

3.1 Mapping Instructor Interventions to the Support Function Model . 30

3.1.1 Interventions 1-2: Scenario Initialization and Workflow Establishment . . . . . . . . . . . . . . 32

3.1.2 Intervention 3: Examining Physical Evidence and Exploiting Intercepted Materials . . . . . . . . . . . . 35

3.1.3 Intervention 4: Surprise Briefing Demand by "Angry" Superior Officer . . . . . . . . . . . . . . . . . 37

3.1.4 Intervention 7: Exploitation of Recovered Cache Items . . . 39

3.1.5 Intervention 11: Functional Analysis of Adversary Modus Operandi ................... 41

3.1.6 Intervention 13: Stolen Torpedo Hypothesis Brainstorming and ACH Methodology . . . . . . . . . . . . . . 43

3.1.7 Intervention 14: Cryptography Lesson, Exploiting Crypto and ELINT . . . . . . . . . . . . . . . . 45

3.2 Analyst Team Receptivity to Instructor Interventions . . . . . . . . 47

4. Discussion . . . . . . . . . . . . . . . . . . . . . 49

4.1 Scenario Design . . . . . . . . . . . . . . . . . . . . . 49

4.2 Role of Broadening Checks . . . . . . . . . . . . . . . . 50

4.3 Synthesis of Findings . . . . . . . . . . . . . . 51

References ............................. 52 


\section{LIST OF TABLES}

Table

Page

3.1 Process tracing tables for intervention 1 on day $1 \ldots \ldots 33$

3.2 Process tracing tables for intervention 2 on day $2 \ldots \ldots . \ldots 34$

3.3 Process tracing table for intervention 3 on day 2 afternoon. . . . . . . 36

3.4 Process tracing table for intervention 4 on day 2 afternoon. . . . . . 38

3.5 Process tracing table for intervention 7 on day 3 midday. . . . . . . 40

3.6 Process tracing table for intervention 11 on day 4 afternoon. . . . . . 42

3.7 Process tracing table for intervention 13 on day 5 morning. . . . . . . 44

3.8 Process tracing table for intervention 14 on day 5 midday. . . . . . 46

3.9 Summary table of analytic team receptivity to instructor interventions. 48 


\section{LIST OF FIGURES}

Figure

Page

1.1 A simplified depiction of IAS as an iterative broadening and narrowing process of convergence, contrasted against an example of premature closure in IAS. . . . . . . . . . . . . . . . . . . . . 9

1.2 A simplified depiction of a support function model for IAS. Copyright ManTech SMA - CSEC (used with permission) . . . . . . . . . . .

3.1 A timeline depicting analytic windows of opportunity for revision within the scenario. . . . . . . . . . . . . . . . . .

4.1 A version of the Support Function Model with Instructor Interventions mapped to it. . . . . . . . . . . . . . . . . 


\section{CHAPTER 1}

\section{INTRODUCTION}

Information Analysis and Synthesis (henceforth "IAS") is a type of cognitive work that plays a key role in many high-performance, complex, and mission-critical domains. These can range from tactical military intelligence to scientific or technological forecasting, business and financial intelligence to national strategic counterterrorism, and include areas as disparate as geopolitical policy analysis to computer network intrusion detection. In essence, IAS is the inferential determination of the best explanation for uncertain, contradictory, and incomplete data (Patterson, Roth, \& Woods, 2001). The tradecraft of IAS domains has been described as being both an art and a science, and can vary greatly from discipline to discipline. Despite this great diversity, research in cognitive systems engineering has demonstrated that the majority of these domains share a core set of underlying functions and characteristics (Elm et al., 2005; Patterson et al., 2001; D. D. Woods, Patterson, \& Roth, 2002). The goal of this study is to deepen the understanding of the differences between weaker and stronger instances of IAS as a general form of cognitive work.

The specific subject of this study is the military intelligence domain as one instantiation of IAS. As a preliminary exploratory study, we performed elicitation with a diverse set of intelligence practitioners by using a "critiquing as cognitive task 
analysis" methodology (Miller, Patterson, \& Woods, 2001a). The purpose of this exploratory study was to identify cognitive vulnerabilities in the IAS process, familiarize ourselves with some of the domain complexities, and to calibrate our understanding of what made an intelligence assessment weaker or stronger. The main investigative effort, however, took the form of a scaled-world study (D. D. Woods, 1993; D. Woods, 2003; D. D. Woods \& Hollnagel, 2006). In particular, we leveraged a real world tactical intelligence training exercise as a natural laboratory for investigating the contrasts between weaker and stronger IAS.

\subsection{Why a natural laboratory?}

"It is notoriously difficult to generalize [experimental] laboratory findings to real-world situations. The relationship between cognition seen as a solitary mental activity and cognition seen as an activity undertaken in social settings using various kinds of tools is not at all clear."

(Hutchins, 1995a)

The above quote from Hutchins succinctly captures our motivation for studying the cognitive work of IAS in natural settings. Our generic empirical method is to stage and shape the conditions of observation in a scaled-world scenario, while employing ethnographic techniques of investigation. With this approach, it is crucial that the scenario authentically reflects the complexities of the real domain, while enabling the researcher to embed specific investigative probes into the environment (D. D. Woods \& Hollnagel, 2006).

This particular scenario is a found problem; a tactical intelligence training exercise from the US Army Intelligence Center at Ft. Huachuca, AZ. Because of the preexisting training goals of the exercise, we did not have explicit control over its design, 
and therefore had to work within its inherent constraints. Fortunately, the training goals and the research goals mutually included the establishment of a sufficiently authentic and complex premise under which the analyst teams must operate.

To be further reflective of the real domain, this particular exercise is administered in a team-based, distributed work setting, much like how the work of IAS takes place in most disciplines. One advantage of studying distributed work is that typically internal cognitive processes must be externalized in some form to enable collaboration between multiple practitioners. This creates more opportunities for meaningful observations of the cognitive work

The analyst teams who participated in the scenario were composed of active military intelligence officers midway through a mandatory 20 -week course intended to transition them into analytic leadership roles. As military intelligence captains, they serve as analysts and analyst supervisors with a bachelors level education and an average of four years of military service. The class of 40 captains is randomly divided into four independent teams for a fictional counter-insurgency scenario based in World War II era Great Britain. Each team simultaneously executes the same scenario under the supervision of an instructional training cadre. The training cadre is composed of more senior officers with significant intelligence experience, and play the roles of both commander (receiving analytic assessment briefings from the teams) and instructor, or mentor. The training cadre is also responsible for administering and pacing the exercise, and simulating interactivity. 


\subsection{How does the functionalist perspective help one under- stand complex domains?}

Throughout this study, we adopt a functionally-abstract, system level perspective as a way to approach IAS as a joint cognitive system, as described by Potter (2002). This relies on the assumption that the work in the system is goal-directed. This perspective begins with a function-based goal-means decomposition of the system, which is a formalism for representing the cognitive work domain as an abstraction hierarchy or network:

"A work domain analysis is conducted to understand and document the goals to be achieved in the domain and the means available for achieving them (Vicente, 1999). The objective of performing this analysis is to develop a structure that links the purpose(s) of individual controllable entities with the overall purpose of the system. This includes knowledge of the system's characteristics and the purposes or functions of the specific entities. The result of the first phase is a Functional Abstraction Hierarchy $(\mathrm{FAH})$, a multilevel recursive means-ends representation of the structure of the work domain, that anchors the first span of the bridge.

The work domain analysis is performed based on extensive interactions with expert practitioners in the domain and includes face-to-face interviews with the experts, watching the experts work in the domain, verbal protocol techniques, and other CTA and Cognitive Work Analysis (CWA) methods (Potter, Roth, Woods, \& Elm, 2000; Vicente, 1999). In practice, building an FAH is an iterative, progressively deepening process. It starts from an initial base of knowledge (often very limited) regarding the domain and how practitioners function within it. Then, complementary techniques are used to expand and enrich the base understanding and evolve a function-based model from which ideas for improved support can be generated. This process is highly opportunistic.

Researchers should ultimately discover an understanding of the goaldriven characteristics of the domain that will lead to an understanding of the decisions practitioners are faced with in the domain. One might start by reading available documents that provide background on the field of practice (e.g., training manuals, procedures); the knowledge gained will raise new questions or hypotheses to pursue that can then be addressed in interviews with domain experts, and it will also provide the background 
for interpreting what the experts say. In turn, the results of interviews or exercises may point to complicating factors in the domain that need to be modeled in more detail in the FAH. This provides the necessary background to create scenarios to be used to observe practitioner performance under simulated conditions or to look for confirming example cases or interpret observations in naturalistic field studies.

The resulting FAH specifies the domain objectives and the functions that must be available and satisfied to achieve their goals. In turn, these functions may be abstract entities that need to have other, less abstract or less aggregated functions available and satisfied so that they might be achieved. This creates a decomposition network of objectives or purposes that are linked together from abstract goals to specific means to achieve these goals.

The FAH provides a framework for making explicit the goals to be achieved in the domain and the alternative means available for achieving those goals. High-level goals, such as impacting a critical function, are decomposed into supporting lower-level subgoals. This provides the basis for identifying - through subsequent steps in the analysis and design process - the cognitive activities that arise in the domain and the information needed to support those decisions. The FAH enables the designer to determine where decision making is likely to be difficult due to the fundamental characteristics of the domain. For example, the FAH helps convey places in problem space where objectives compete with each other (e.g., where choices have to be made that require some level of sacrificing of one objective to achieve another, perhaps more heavily weighted, objective), or otherwise constrain each other (e.g., where the satisfaction of multiple goals needs to be considered in determining the best course of action).

There are a growing number of examples of successful systems that have been developed based on a work domain analysis. Examples of functional abstraction hierarchies and how they were used to design new visualizations and Decision Support Systems (DSSs) can be found in (Roth, Lin, Kerch, Kenney, \& Sugibayashi, 2001) and (Potter et al., 2000). Examples of the application of this approach to model cognition and collaboration and to develop new online support systems in time pressured tasks such as situation assessment, anomaly response, supervisory control, and dynamic replanning include domains such as military intelligence analysis (Potter, McKee, \& Elm, 1997), military aeromedical evacuation planning (Cook, Woods, Walters, \& Christoffersen, 1996; Potter, Ball, \& Elm, 1996), military command and control (Chalmers, Easter, \& Potter, 2000), railroad dispatching (Roth et al., 1998), and nuclear power plant emergencies (Roth et al., 2001)." 


\subsection{How does one understand the generic cognitive work of Information Analysis and Synthesis?}

A useful way to understand a domain is to examine what makes the work of the domain difficult. Information Analysis and Synthesisis the process of analyzing (breaking apart) and synthesizing (putting together into a new whole) complex and disparate information to produce insight or assessments in support of a larger organizational goal or mission. It is subject to similar patterns in multi-threaded work that occur in many other diverse high-stakes domains (D. D. Woods \& Hollnagel, 2006). Practitioners constantly have to cope with information overload. Distributed work environments mean that coordination challenges can arise. Interaction with clumsy automation impedes workflow. Time pressure can lead to prematurely-narrowed assessments. Practitioners must navigate organizational goal conflicts and double binds. In general, it is apt to characterize the domains of IAS as being highly complex.

As a reflective practitioner, Trent (2005) proposes a set of common cognitive vulnerabilities in military intelligence:

* Mental Set

* Recognition of Relevant Data

* Fixation

* Environmental Pressure

* Trust

* Tool Understanding

* Sustained Attention

* Adversarial Interaction

* Learning 
* Inadequate Hypothesis Testing

* Experience Viewed as Expertise

These vulnerabilities point to potential areas for future study in improving support to IAS.

Some of the unique characteristics of IAS domains, in particular intelligence, relate to the adversarial nature of its focus. Adversarial interaction with an adaptive opponent brings with it the cognitive complexity of detecting and understanding deliberate deception (Trent, 2005). In addition, special challenges to analytic workflow are introduced by operating in a security classified environment, as is frequently the case with IAS (Bodnar, 2003).

Cognitive systems engineering research has shown that at the functional level, many commonalities in cognitive work exist between the disparate domains where IAS takes place. An advantage to this is that uncovering leverage points of support for the cognitive work of IAS in one domain can usually lead to rapid advancements in understanding across other IAS domains. This functional perspective is useful because it is goal-oriented and captures the purposes of the IAS work, as well as the means available to achieve them (Hollnagel, Mancini, \& Woods, 1988; Potter, Elm, Roth, Gualtieri, \& Easter, 2002; D. D. Woods, 2003; D. D. Woods \& Hollnagel, 2006). This perspective can also be represented as a simple framework to help make initial sense of observations.

\subsubsection{What is convergence?}

Success in IAS is characterized by the concept of Convergence, an iterative narrowing and broadening process. Narrowing is the process of seeking analytic closure 
of the solution space. Broadening is the process of guided expansion of the solution space to incorporate multiple perspectives, and should be complementary to narrowing. Convergence upon an explanation is the desired end goal of a sufficiently rigorous, iterative narrowing and broadening process.

Successive cycles of narrowing and broadening produce convergence and avoid Premature Narrowing, a great risk of failure in IAS. A prematurely narrowed assessment is immature, brittle, and doesn't include a diversity of perspectives on the problem. The difference is that a convergent assessment balances narrowing processes in cognitive work with complementary broadening, while a prematurely narrowed assessment has insufficient broadening.

\subsubsection{How does rigor aid the determination of process qual- ity?}

A successfully convergent analytic process supports the judgment of rigor of an assessment. High performance organizations depend upon highly-rigorous information analysis and synthesis. Organizations supported by highly-rigorous assessments are more resilient in the face of challenges or surprise, and are better able to adapt to the world. The sufficiency of an assessment's rigor is judged relative to the the goals of the stakeholders and constraints of the environment. Many things impact this judgment, such as the process followed, sources used, peers consulted, quality of cross-checking, supporting materials, asset constraints, stakeholder expectations, and the quality of dissemination (Patterson et al., 2001; Hollnagel, Woods, \& Leveson, 2006).

In the face of rapidly proliferating data availability - and the resulting data overload deluging IAS practitioners - the value of facilitating the judgement of rigor has 


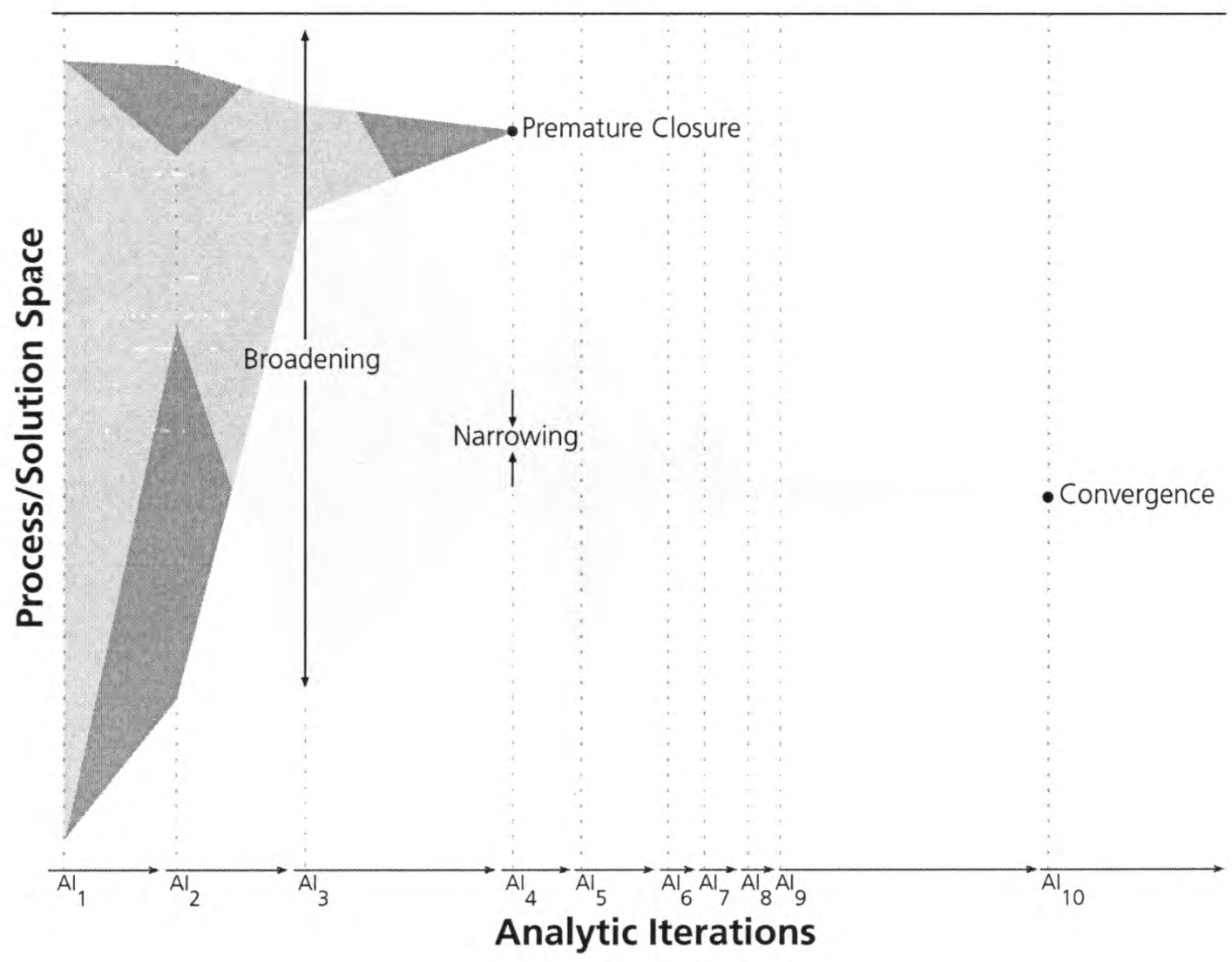

Figure 1.1: A simplified depiction of IAS as an iterative broadening and narrowing process of convergence, contrasted against an example of premature closure in IAS. 
increased dramatically. Increasingly, the tendency to perceive the increased affordance of data accessibility as being resultant in good process makes it easy for novice practitioners to get trapped in shallow analysis. Having a better understanding of rigor is one analytic safeguard to be leveraged against this constant risk. This area is just beginning to be explored, and is ripe for future study (Zelik, Patterson, \& Woods, 2007).

\subsection{What is the support function model of Information Anal- ysis and Synthesis?}

The convergence conceptualization of IAS evolved into a Support Function Model for IAS. First, based on a synthesis of prior work (Miller, Patterson, \& Woods, 2001b; Patterson et al., 2001), the Support Function Model is a model of interacting functions that comprise inferential analysis. This intelligence analysis model is an iterative broadening and narrowing convergent process. This model is a "closed loop" model of interacting functions (not a sequence of tasks), and includes three generic process areas: Down Collect functions are focused on collection of an essential, representative, "on analysis" sample from available data; Conflict and Corroboration functions are focused on the construction of accurate interpretations of the findings from the Down Collect process; and Hypothesis Exploration functions are focused on the construction of coherent stories or hypotheses to explain the interpretations of the findings. These functions were identified as the cornerstones for effective intelligence analysis. All of these functions are "narrowing" functions, in that they focus on a reduction of the problem toward "the answer".

In between these three support function areas are phases of broadening checks (Elm et al., 2005). These serve as cross-checks against the predominantly narrowing 
aspects of the primary functions. The natural tensions between broadening (to fully explore all options) and narrowing (to a finding) at each "edge" (between the three primary functions) defines success or failure in reaching the analytical conclusion. Convergence, then, is a stable balance between broadening and narrowing while premature closure (a typical characterization of analytical error) is a lack of broadening.

These transitional broadening areas include sets of requirements that support the interaction of a coupling or transition of the primary functions. These include:

* Down Collect to Conflict and Collaboration broadening is focused on revising the down-collect results based on interpretations from the Conflict and Collaboration process as well as generating new interpretations from revised Down Collect results.

* Conflict and Collaboration to Hypothesis Exploration broadening is focused on revising the interpretations based on alternative hypotheses under consideration as well as generating new hypotheses based on the interpretations.

* Hypothesis Exploration to Down Collect broadening is focused on revising the down collect process based on alternative hypotheses under consideration as well as on generating new alternative hypotheses based on revised Down Collect results.

Elm's hypothesis is that in order to be effective, support must be provided for explicit control of this convergent, broadening and narrowing proccss. Thus, the Support Function Model defines a system design goal decomposition model of support requirements for these functions. Requirements arise from two fundamentally different but complementary dimensions. First, there is the decomposition of system goals into sub-goals based on the framework defined by the convergent broadening and narrowing model of intelligence analysis. Second, that system goal decomposition 
model is augmented with requirements specific to the design of a joint cognitive system.

Within each of the primary functions (Down Collect; Conflict and Corroboration; Hypothesis Exploration) is a specific set of support functions for accomplishing the primary function. This integration results in a unique set of system requirements that define the decision support requirements for IAS as well as support for effective human-automation interaction. This is a significant breakthrough in the application of lessons learned from many years of research on human interaction with complex systems.

\section{Finding the Decision Support}

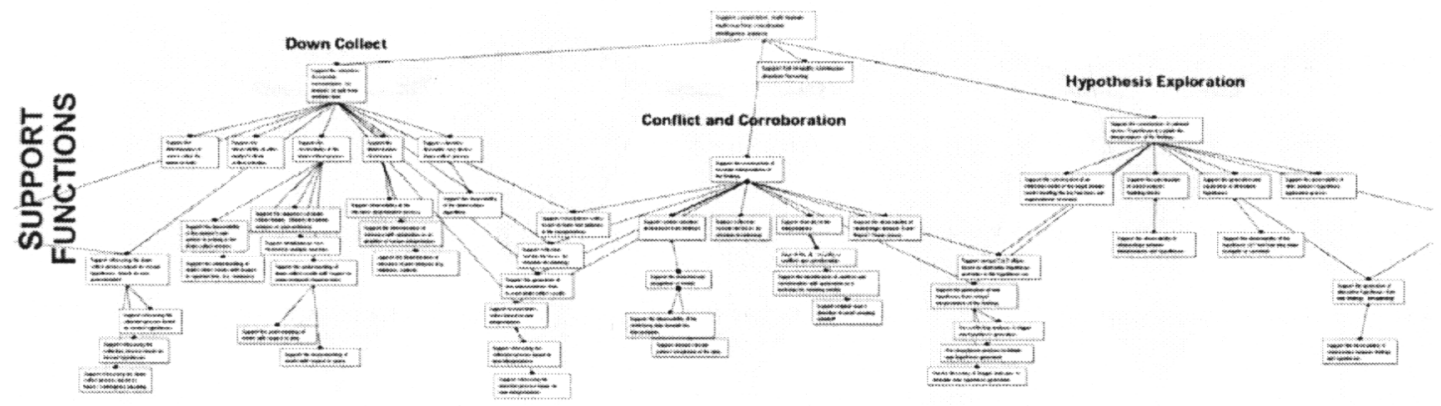

Figure 1.2: A simplified depiction of a support function model for IAS. Copyright ManTech SMA - CSEC (used with permission)

\subsection{How do instructor interventions serve as broadening checks?}

Insights from the evolution of this model led to the concept of a broadening check as being a key safeguard against a common vulnerability of IAS, premature narrowing. Broadening checks are a critical aspect of expertise in IAS to avoid getting trapped 
in shallow analysis. A broadening check is a special class of a cross-check. Crosschecks are a way to increase the diversity and integration of relevant perspectives into an assessment or decision. Cross-checking is a critical component of analytic rigor because it can enable detection of erroneous assessments or actions while negative consequences can be mitigated or eliminated. (Hutchins, 1995b; Patterson et al., 2001; Patterson, Woods, Cook, \& Render, 2005; D. D. Woods, Johannesen, \& Cook, 1994; D. D. Woods \& Hollnagel, 2006).

This study specifically examines how broadening checks occur in practice. Because of the inexperienced nature of their background, the analyst teams in the exercise were frequently vulnerable to premature narrowing. To counter this, one of the common functions taken on by the instructors was to provide broadening checks. This manifested itself in periodic instructor interventions into the team analytic process. This created an observational benefit: interventions were easily-identifiable discrete events which could have their impact on the team analytic process traced in subsequent observations.

In general, instructor interventions are an interesting source of data because they speak to the goals of the training exercise, and illustrate one way expertise is passed down within an organization. Instructor interventions also give an indication of aggregated historical points of difficulty in the scenario, status and progress of teams, and common cognitive vulnerabilities in IAS.

The instructors played several interesting roles in the exercise. Their main role is to instruct the analyst teams in the doctrinal goals of the training. This includes tactics, techniques and procedures specific to appropriate areas of the scenario, reinforcement and clarification of previous training, and performance feedback. 
The instructors also play an administrative and diagnostic role relative to maintaining team engagement in the scenario. This includes preventing analyst teams from getting "stuck" or diverting too far from the normative analytic goals in order to maintain the value of the exercise. This judgement requires diagnosis of team analytic diversion and anticipation of common scenario pitfalls and analytic vulnerabilities. Instructor steering and guidance in these areas provides insight and leverage into areas of weak and strong analytic process.

Related to scenario administration, instructors are also responsible for maintaining continuity across the multiple days of the scenario. This involves simulation of adversarial, command, and federated interactivity and control of the pacing, tempo, and tone of the exercise.

\subsection{Why is a field study of the military intelligence domain an interesting laboratory for studying IAS in general?}

Since the events of September 11,2001, the intelligence community has been criticized for perceived "failures" in a predictably reactive response mode. This has led to a climate of aggressive transformation in tradecraft processes, doctrine, culture, and tools. Frequently in transformative efforts - and especially in the national defense arena - technology and automation are seen as the remedy to or savior of practitioners deemed too inefficient, inconsistent, or overextended to perform as desired.

Often, large software tool development efforts are undertaken without sufficient understanding of the core functions and characteristics of the work of the target domain or even a basic regard for the principles of joint cognitive system design. This usually results in tools that don't adequately support - or worse, hinder - the cognitive work of the domain. In a large part, this is due to current software requirements 
development and design processes being unable to adequately capture or represent the cognitive work of the domain. Practitioners are left to bridge the gaps in support themselves by instituting workarounds, and the particular tool quickly falls out of favor. This doesn't change the need for a particular type of support, and a new project is commissioned to rectify the shortcomings of the past, only to generally fail again in the same repeating pattern. In the end, throwing assets and technology at the problem only serves to aggravate the situational shortcomings without first having a domain-relevant and context-sensitive understanding of how success is achieved.

As a naturalistic observation-based study, this research attempts to capture an authentic domain understanding. Due to the aforementioned shift of strategic focus in the world, practitioners are increasingly being faced with doctrinally-unfamiliar situations with vaguely-defined goals. This period of adaptation produces changes in the supporting functions and goals of intelligence domains, and these changes provide a window into the meaningful underlying patterns of cognitive work in the domain. Understanding these patterns allows their use in guiding change and innovating new possibilities for cognitive support in concert with other stakeholders (D. D. Woods, 2003).

Several unique characteristics of this particular study help clarify potential complexities in understanding complex domains such as Information Analysis and Synthesis:

* The actual world being observed is a scaled world; a bounded version of the real world with enough shared characteristics and complexity so as to be perceived authentically by actual domain practitioners. The scaled nature of the world allows some control over the situations and consequences that the participants are faced with, giving a window into otherwise unpredictable or unobservable scenarios. 
* "Low tech" scenario work constraints make the analytic process more observable than a computerized, virtual workspace would be.

* Four independent analyst teams working the same mission and scenario simultaneously allows for repeated, parallel observations to compare across.

* Continuity of multiple (6) days gives opportunity for multiple cycles of analytic process to occur. This provides insight into how practitioners are managing continuous work in time and coping with multiple threads. Researchers get to see how they manage the work, how the integrated process fits together, and effects due to time pressure and pacers in the scenario.

* The administration of tailored guidance and feedback from a consistent instructor cadre gives insight into both historical points of analytic vulnerability and specific team performance issues.

* The scenario of the exercise evolves, escalates, precipitates, and reverberates, allowing to researchers to see interlinking between multiple cycles because of feedback from the world, as well as the role of adversarial interaction in the dynamics.

* Feedback loops in the daily team briefings to commander (instructor) allow observation of opportunities for revision and replanning.

* Observation of analytic teams building on previous assessments and/or revising shows the connection between analysis and replanning.

* Cascading effects become evident in seeing how assessments get updated, and seeing revision process play out over multiple cycles as new events occur.

* Natural pacers (tempo) occur both with the briefings as a tempo keyframe and the issuance of new reports or events in the scenario.

\subsection{What are the general patterns in the multi-threaded work of IAS?}

In addition to the aforementioned unique characteristics of this particular domain, several generic patterns in cognitive work also play out in this exercise: 


\subsubsection{Tempo}

Tempo become relevant in how external events pace practitioner activities, and how periods of event driven activity are intermingled with periods of self-paced activity (D. D. Woods \& Hollnagel, 2006).

\subsubsection{Escalation}

Escalation encompasses the process of how situations evolve from routine to exceptional, producing an increase in cognitive and coordinative demands, thereby making penalties of poor support for work more apparent (D. D. Woods \& Hollnagel, 2006).

\subsubsection{Coupling}

Coupling is the degree of interconnections between parts of process - which influences the creation of side effects of an event or anomaly, resulting in challenges to coordination and resilience (D. D. Woods \& Hollnagel, 2006).

\subsubsection{Support Function Network as a tool for uncovering coupling}

The IAS support function network helps map couplings across functional and physical levels of descriptions and captures how disrupting events can produce cascades of effects (D. D. Woods, 1994).

\subsubsection{Premature Narrowing}

Premature narrowing is the danger of becoming stuck in one assessment and being unable to revise even as new evidence presents itself or the situation changes (D. D. Woods, O'Brien, \& Hanes, 1987). Strategies for avoiding this vulnerability can be seen as part of the development of expertise and coordinative mechanisms in a JCS 
(Cook, Render, \& Woods, 2000). Studies by Gettys et al., Patterson et al., and Elm et al. have shown that one of the key strategies for doing this is by broadening the set of possible explanations to be covered (cited in D. D. Woods \& Hollnagel, 2006).

\subsubsection{Reframing}

In an ongoing situation, replacing a frame is harder than simply revising an assessment for practitioners. Data noticed about the world trigger frames that account for that data and trigger search for additional data. In parallel, framing orients the observer to the world, guiding what counts as data (D. D. Woods \& Hollnagel, 2006).

\subsubsection{Dilemmas}

This includes goal conflicts and double binds, tradeoffs, and interactions (D. D. Woods et al., 1994).

\subsubsection{Over-simplifications}

This is the stripping away important nuance, detail, or meaning during an assessment. 


\section{CHAPTER 2}

\section{METHODOLOGY}

"There is nothing quite like looking, if you want to find something. You certainly usually find something, if you look, but it is not always quite the something you were after." - J.R.R. Tolkien

For this study, we used several complementary methods to generate a meaningful understanding of the work of IAS (Potter et al., 2000). We chose two classes of methods: a natural history technique, and a scaled-world study (D. D. Woods \& Hollnagel, 2006). For the natural history technique, we employed a critique study method (Miller et al., 2001a; Miller, Patterson, \& Woods, 2006) paired with unstructured elicitation. For the scaled-world study, we leveraged a scenario from an existing real-world training exercise as a natural laboratory.

\subsection{Critique Study Method Paired With Elicitation}

"The use of critiquing as a CTA methodology walks through a novice's process on a task in order to serve as a probe for elicitation of expert commentary. This technique takes advantage of skill in critiquing, which is often conducted by more skilled practitioners in order to train less skilled practitioners, to provide insight into expertise. It is an alternative that can be used when it is not possible to observe work because of access restrictions, low frequency or unpredictability of target observation events, or difficulty in recruiting experts who wish to be evaluated on their task performance. It also allows for estimation of variability because multiple experts can critique a single novice's process." (Miller et al., 2001a) 
We were interested in comparing perception of analytic rigor between expert analysts and novice analysts as a way to understand complexities and vulnerabilities in IAS. We found the critique method to be appropriate for this because of its facilitation of generating expert commentary. We introduced a slight variation by using the method with both expert and novice analysts as a point of comparison, and by having the analysts assume the persona of an "analyst supervisor" while giving the critique. Using both expert and novice analysts also allowed us to examine generational changes in analytic practice. In many cases, the sample analytic process being critiqued becomes an excellent artifact to base further elicitation around, trigger recall of related events in the practitioner's experience, and give a frame of reference from which to base other relevant examples.

Our prior research with intelligence analysts had primarily been in the tacti$\mathrm{cal} /$ military domain, so a major goal for the critique study was to work with strategic/national domain analysts. This way, we hoped to gain a broader understanding of the cognitive work of IAS in general across domains, and also of the specific domain differences between tactical and strategic intelligence analysis.

In all, 3 highly-experienced and 2 less-experienced strategic analysts were interviewed, with an average of 2 hours per session. The less-experienced analysts were interviewed with an eye towards how they might best benefit from support to accelerate their analytic learning curve. The highly-experienced analysts came from a variety of strategic analytic specializations in order to provide broad coverage of the different types of work going on within the organization.

Because of the restricted access nature of most strategic intelligence work, the critiquing study elicitation technique is valuable for avoiding the constraint of obtaining 
appropriate security clearance. Without this constraint, our desired approach would normally be to observe practitioners while they were working to understand their challenges in context. The use of the critique method facilitated the creation of a safe (unclassified) but authentically-relevant context for the practitioncrs to immerse themselves in that served as an adequate substitute for direct workspace observation. This allowed us to obtain good "grounded" data about what analysis is as a process without actually having the practitioners simulate or do the task themselves (which takes more effort, is hard to do in an unclassified way, and is usually less comfortable for subject matter experts).

In the inaugural use of the critiquing study method (prior to this study), a "first day" analyst (not yet cleared) from a military intelligence agency analyzed publiclyavailable reports about a foreign space agency's recent rocket launch failure, while the researchers observed him prepare a briefing on the causes and impacts of the incident. The work context was a computerized information retrieval system containing a "canned" database of a few thousand documents. The analyst's process and briefing was recorded and used as the critiqued case in subsequent deployments of the method with expert practitioners.

We used this same critiquing method in the current study with a group of strategic intelligence analysts, but in addition to asking them to critique the process that a novice used to analyze the incident, we also tried to explore differences between the example process, and the practitioner's normal process. Participants were read the transcript from the novice analyst's process of producing a briefing on topic, and asked to comment about how closely analogous the process was to their own. This included questions about tools, data types, reporting characteristics, and other 
potential alternative unclassified scenarios that might be more representative of their work than the current example. This served to build up a corpus of cases for future study and to further enrich our understanding of different domain complexities and analytic vulnerabilities across IAS.

\section{2 "Northernstar" Scenario Scaled-World Study}

For the scaled-world study, we leveraged a scenario from an existing real-world training exercise as a natural laboratory. The scenario used in this "Northernstar" exercise is based on a hypothetical stability and support operation (SASO) in the tactical intelligence domain. Specifically, it focuses on intelligence in support of counter-insurgency operations. The premise is an alternate history of World War II, in which the German army successfully invades Great Britain. The participants are captain-level military intelligence officers, midway through a multiweek training course intended to transform them into analytic team leaders. They are split into four teams of 10-15 officers for the purposes of the exercise. The analyst team partipants play the part of a mid-level German intelligence cell charged with quelling an insurgency. The instructor cadre is composed of high ranking, more experienced intelligence officers. However, they play three roles in the exercise - instructor, commander, and administration of the interactivity in the scenario.

Prior to the exercise, all teams were provided an overview briefing by the instructor cadre that described the general situation and constraints. Teams were then assigned to separate rooms, each equipped with dry erase boards, maps, overlay material and four computers with only Microsoft Office applications. The exercise was structured such that the four analyst teams were working independently and in parallel over 
a 6 day period. This created opportunity for repeated, parallel observations across the teams. To begin, each team received a damaged collection of paper bits that was intended to replicate the remnants of information from the last intelligence cell which had recently been "destroyed." This served as a way to introduce them more realistically into joining an analysis in progress instead of starting from a blank slate. Teams were given an initial period of four hours to sort through their information, after which they received a new report, or serial, approximately every two hours. These serials represented a variety of events occurring in the world that the teams had to analyze and act on, triggering analytic windows of opportunity within which to make or revise assessments. Teams were to analyze the available data and task resources for further collection based on their assessments. At the end of each day, teams briefed their assessments to an instructor acting as the commander.

Each serial was designed to provide realistic reports of activity representative of a counterinsurgency in 1940s Great Britain. Because each report had certain normative interpretations and multiple other suboptimal interpretations, they served as embedded event probes with which to elicit behavior indicative of various analytical vulnerabilities. However, the ethnographic observation of this required that the observers had a nuanced understanding of both the scenario itself and the characteristics of the cognitive work of IAS.

Since all teams received the same probes at roughly the same time, they served as unique opportunities to observe repeated measures between the groups. However, this also produced an observational coordination bottleneck. Exercise continuity over multiple (six) days allowed the scenario and team analytic iterations to evolve and build upon previous assessments. In the same way, the teams were also presented with 
opportunities to revise or throw out previous assessments. At various points in the scenario, the teams would receive instructional, analytical, and situational feedback from a member of the instructor cadre. A pattern of standing feedback loops arose from regular daily briefings to the lead instructor (in a commander role) and with scenario evolution, branching, and pacing. A final briefing on the last day led to a pass/fail rating for the exercise and extensive feedback from the instructors on their overall process.

Analyst teams started the six day exercise each day at 0830 , working continuous 8 hour shifts. In the analytic team spaces, distributed observers sat out of the way of the group with laptop computers and notebooks, and connected wirelessly to the central command computer. Observers employed ethnographic observation methods and precalibrated behavior codings to record data. Going into the first day of observation, network and chat connections were established. Throughout the day's events, a single expert domain practitioner on the observation team (SME) and other observers in a "command center" could immediately clarify any questions or confusion as they arose. Throughout each day, chats, video, pictures, and audio were transferred to the central machine. Raw chat data was distributed and reviewed by each observer. General trends in the chat transcripts were monitored and specific changes were made across the groups. After each day of the exercise was over, the observation team met and revised the recording protocol based upon lessons learned during the day. Afterward each observer was responsible for integrating their data and summaries into a structured scenario map of the day's events, and the next day's observations, trends and procedures were reviewed. 
The observations and supporting data were compiled into text logs and spreadsheets for further analysis. In this way, the focus of externalizing the cognitive work of the domain was achieved in a natural, plausible, and unobtrusive way, which could then be later analyzed with a process tracing protocol. For this particular study, episodes in the logs where the instructors had intervened in the team analytic process were extracted, and a process tracing protocol analysis was used to delineate seven categories for each analytic "window of opportunity": Day/Time, Team Number, Mindset/Context Summary, Description of Intervention, Receptivity, Actions/Responses, and Mapping to Support Function Model node(s). This gave structure to the data and helped to isolate the effects of the instructor interventions.

\subsubsection{Methodological Innovations}

In the course of this study, several methodological innovations were instituted to help overcome the complexities of investigating distributed cognitive work.

\subsubsection{Prior-Participant Observers}

In order to observe this excrcise, a team of six observers - not formally trained in intelligence analysis - were assembled to conduct the data collection. In order to familiarize the observers to the domain, operational semantics, scenario and anticipated work of the practitioners, the observation team took part in a two-day accelerated version of the same exercise. In this capacity, they performed the same functions and faced the same complexities as the analysts they were about to observe, while also allowing them to become intimately familiar with the scenario. This served to help cue anticipatory points of interest to focus on in the later observations, as well as pre-calibrating observational terminology and granularity. 
In addition, the choice of a "low tech" historical setting for the scenario restricted most of the team analytic work to analog or paper products, with the only exceptions being the permitted use of a single personnel database and office productivity software. A great advantage to this externalized workflow was that it made the analytic process greatly more observable than it would be if the teams were working in a digital computerized medium.

\subsubsection{Distributed Observation Teams}

In order to observe all squads concurrently, one observer was assigned to each squad with two observers establishing a command and coordination post in an adjacent room from which to monitor and facilitate communication between observers. A domain practitioner able to act as a subject matter expert (SME) was present on the observational team, and retained the ability to physically move between the remote observers stationed with the squads and to communicate with remote observers via computer from the command post. This helped in clarifying different domain complexities that arose, and gave the observers near-instant access to domain expertise. This was useful for translating jargon, expanding acronyms, explaining doctrine and processes, and overcoming other numerous observational impediments.

An ad-hoc wireless network was deployed enabling communication between remote observers, the SME, and the command post. Each remote observer used a laptop (Windows and Macintosh platforms) to communicate with the command post over an ad-hoc wireless $802.11 \mathrm{x}$ connection. Observers took notes by having a chat "conversation" with the central command post using commercial off the shelf (COTS) 
asynchronous instant messaging software (Adium, iChat, Trillian: all utilized the ZeroConfig/Bonjour protocol). Inside the command center two to three members of the observation team monitored each stream of incoming observer data. This realtime feedback allowed the command post to coordinate and redirect resources and attention constantly, and specifically at rich probe points in the scenario and to emergent analytic vulnerabilities and behavior. At the end of each day full transcripts of each team's chat logs were combined together with any supplementary multimedia. Each of the chat programs allowed observers to transfer multimedia and text files as well as initiate one-way and two-way audio and video connections with the command post, allowing more robust data collection and providing the command post with a directable remote presence.

The team of observers, while physically distributed, was able to efficiently and effectively observe the analyst teams perform distributed work. Simultaneously, the SME and command post observers coordinated observation teams as instructors introduced new serials, gave specific lessons based on individual team shortcomings, and received briefings. Rather than one observer being overwhelmed by trying to watch an entire team by themselves, we had the capability to have up to nine people observing and analyzing one team as resources or constraints dictated.

\subsubsection{Instructor Interventions as Probes into Broadening Checks}

This study specifically examines how broadening checks occur in practice. Because of the inexperienced nature of their background, the analyst teams in the exercise were frequently vulnerable to premature narrowing. To counter this, one of the common functions taken on by the training cadre was to provide broadening checks. This 
manifested itself in periodic instructor interventions into the team analytic process. This created an observational benefit: interventions were easily-identifiable discrete events which could have their impact on a team's analytic process traced in subsequent observations.

In general, instructor interventions are an interesting source of data because they speak to the goals of the training exercise, and illustrate one way expertise is passed down within an organization. Instructor interventions also give an indication of aggregated historical points of difficulty in the scenario, status and progress of teams, and common cognitive vulnerabilities in IAS. 


\section{CHAPTER 3}

\section{FINDINGS}

The combination of a rich scaled-world scenario, target domain practitioners as participants, and innovative observational techniques allowed for this exercise to become a fruitful natural laboratory for investigating the contrasts between weaker and stronger information analysis and synthesis. In order to trace the analytic processes, analytic windows of opportunity for revision had to be identified. These windows typically were triggered by new events or feedback from the world, as well as from previous instructor interventions (as broadening checks). Teams who risked missing a specific window for revision - either due to a poor analytic process or a particularly hard portion of the scenario - then received an instructor intervention, intended to be a "teachable moment" or divergent course correction in the scenario. From identifying these windows, two major investigatory themes became salient in the resulting data. The first theme dealt with the nature of the instructor interventions within each analytic window, and its relationship to broader IAS support functions. The second theme was concerned with the team's receptivity to the intervention, and their resulting performance. 


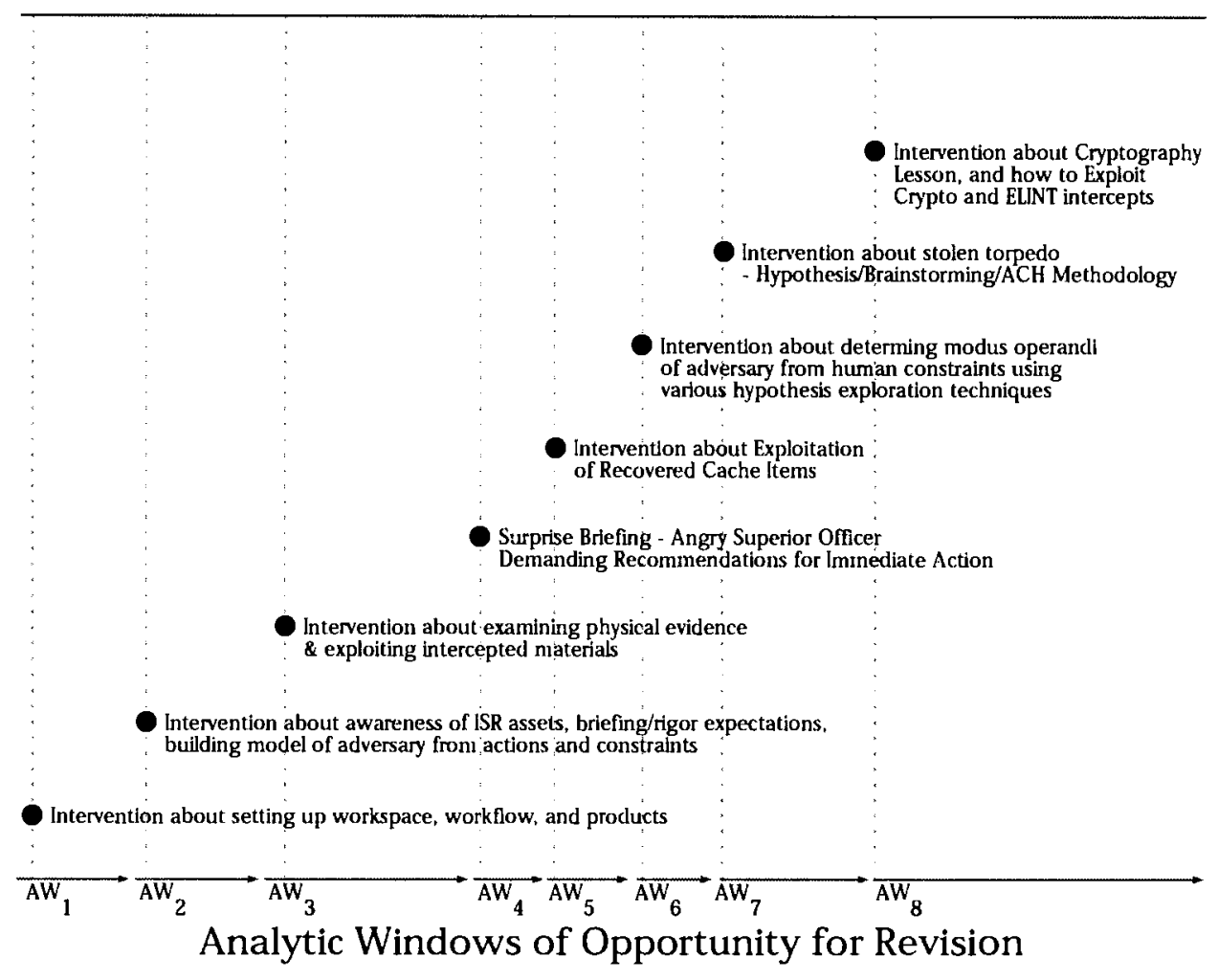

Figure 3.1: A timeline depicting analytic windows of opportunity for revision within the scenario.

\subsection{Mapping Instructor Interventions to the Support Func- tion Model}

We examined the nature of several specifically interesting interventions that served as broadening checks to the team analytic process, and mapped the findings to the aforementioned Support Function Model. The most evident aggregate finding from this mapping was the overwhelming focus that the interventions placed on the hypothesis exploration and conflict and corroboration support function areas. These results could be useful to inform the design of analytic support tools, which currently tend 
to gravitate in contrast more towards the down collect support function area. The importance of providing functional support for the "critical thinking" activities in the conflict and corroboration and hypothesis exploration areas is a key research and application area for future development and exploration.

Comparing data from the critiquing study, we noticed a few differences between the domain of the national or strategic analysts and the observed domain of the military or tactical analysts. Time pressure and action-feedback loop coupling tend to be tighter at the tactical level. Expected levels of product refinement and analytic rigor tend to be higher at the strategic level. The opportunity to directly task collection platforms tends to be greater in tactical intelligence. Strategic level tasking and mission tends to be more ambiguous or open-ended, while tactical tasking is more closely tied to actionable recommendations. In general, however, the cognitive work of the two domains mostly converges, and the findings strongly reinforce the applicability of the Support Function Model as a relevant general framework for understanding IAS. 


\subsubsection{Interventions 1-2: Scenario Initialization and Workflow Establishment}

These interventions dealt with getting the analytic team initially up to speed to join an analysis-in-progress. Specific topics include: TTP for setting up the TOC, workflow, products, awareness of ISR assets, briefing/rigor expectations, building model of adversary from actions and constraints. 
Intervention I: (day I briefing) TTP for setting up the TOC, workflow, products

\begin{tabular}{|c|c|c|c|c|c|}
\hline Team & Mindset Context & Cues/ntergentions & Receptivity & ActionstResponses & Mapping to Model \\
\hline & $\begin{array}{l}\text { Team is still tring to } \\
\text { establish intial analycic } \\
\text { rromentum and team } \\
\text { workflow, and is open } \\
\text { to feectack and intial } \\
\text { framing/scructure. }\end{array}$ & 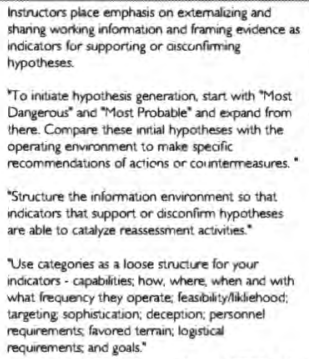 & $\begin{array}{l}\text { Generally high- } \\
\text { duc to intial } \\
\text { scerano } \\
\text { momentum and } \\
\text { lack of } \\
\text { competing } \\
\text { established } \\
\text { workflow. }\end{array}$ & $\begin{array}{l}\text { Team tries to follow } \\
\text { instructor advice, instituting } \\
\text { new team analyic workflow } \\
\text { and beginning to document } \\
\text { prevously verbal interactions. }\end{array}$ & $\begin{array}{l}\text { Mostly Hypothesis Exploration namrowing functions. } \\
\text { Some broadening between Conflict \& Corroboration } \\
\text { and Hypothesis Exploration, and between Hypothesis } \\
\text { Exploration and Down Collect } \\
\text { 35.I Support the observabiliny of relationships } \\
\text { between fincings and hypotheses } \\
3.4 \text { Support the observability of other analyst's } \\
\text { hypothesis exploration process. } \\
\text { 3.1 Support the construction of an inferential } \\
\text { moded of the target domain (understanding the key } \\
\text { functions and organizational structure). } \\
272 \text { Use the discovery of 'ungger' indicator to } \\
\text { stimulate new hypothesis generation }\end{array}$ \\
\hline \multicolumn{6}{|c|}{$\begin{array}{l}\text { sidebar: MI doctrinal expectation of analysts to rapidily develop an adversarial COA pus } \\
\text { premature closure framing effects. }\end{array}$} \\
\hline & $\begin{array}{l}\text { Analysts are anvious to } \\
\text { create siructure in the } \\
\text { data. }\end{array}$ & $\begin{array}{l}\text { Instructors urge analysts not to start with too many } \\
\text { assumptions about the adversary (mirror bias). } \\
\text { Iry to determine capabilities based on actions } \\
\text { instead of fitting adversary to pre-existing structure. }\end{array}$ & $\begin{array}{l}\text { Moved - team is } \\
\text { fixated on how } \\
\text { to create } \\
\text { nomal doctrinal } \\
\text { products instead } \\
\text { of thinking } \\
\text { about whether } \\
\text { adversary force } \\
\text { structure } \\
\text { suppors the } \\
\text { nomal } \\
\text { products }\end{array}$ & $\begin{array}{l}\text { Team drops product fixation. } \\
\text { but doesn't pursue analytic } \\
\text { undow reacily. }\end{array}$ & $\begin{array}{l}2 \text { Support the consinution of accurate } \\
\text { interpretations of the findings } \\
2.4 \text { Support diversity in the interpretations of data. }\end{array}$ \\
\hline & $\begin{array}{l}\text { Team begins working in } \\
\text { space as it is presestied } \\
\text { to them, instead of } \\
\text { acapting a to their } \\
\text { needs and to facirtaxe } \\
\text { organzation and } \\
\text { workflow. }\end{array}$ & $\begin{array}{l}\text { instructors show analyss how to set up physical } \\
\text { workspace to support process and product flow. }\end{array}$ & $\begin{array}{l}\text { Generally high- } \\
\text { due to initial } \\
\text { scenano } \\
\text { momentum and } \\
\text { lack of } \\
\text { competing } \\
\text { established } \\
\text { workflow. }\end{array}$ & Tearn revses $T O C$ secup. & 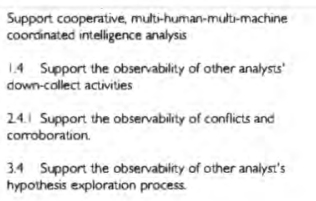 \\
\hline & $x$ & $x$ & & $x$ & $x$ \\
\hline
\end{tabular}

Table 3.1: Process tracing tables for intervention 1 on day 1. 
Team is unable to Elsentially the instructor teaches the team how to do a function

irtegrate analysis of analysis of an adversary, based on ther tactic capabilites, types of

picture of the adversary gNes an example of how to tum that aralysis into counterrveasures.

Team wants to use their adversarial means of this particular arathys is to determine likely

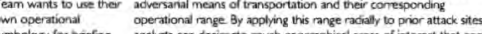

symbology for briefing

suspected adresgate rough geographicat

Instructors raintain a separate focus on operational symbology (well. defines) and symibobogy lor presentation to supeniors (standardized

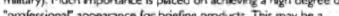

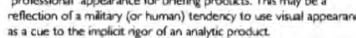

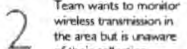
the area but is irian
of their collection assets.

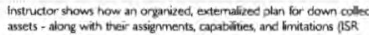

plan) - tan help rocuke

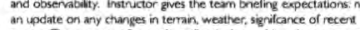

an update on any changes in ternan, weather, segrilance of recerd

both long term and short term COA's, ISR plans, and PIR

Team is having tro
structuring their

differentiate sopport bor

Insthxtior urges then to look at what pattems re created by the

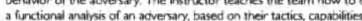

types of targets, constraints, and intercepted materials and persomvel

Then he gives in example oi how to tum that znalysis into

countermeasures. The speofic focus of this particutar analysis is to

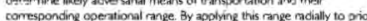

attack sites, anathsts on designate rough geogaphical areas of interes that contain suspected acversaria direct action groups, instructor shows tean how to interpret data to discrimate specilic hypothese

being supportes over othes

any infomation dhedy araince of conducting a full exploitation of
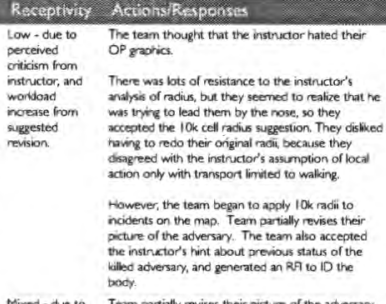

Mixed - due to

rome resistance
to overtum

to overtim
current mindset.

Tem partially revises their pictive of the adversen.

31. Soport the

construction of an inferentis

model of the target domen

(understanding the key

struture;

15 support the observability
of the down-colled process

1.4 Support the obsenability of other analysts' doum
collect activties

221.25 upport domain relevant patten recognition

32.1 Support the
oxsenvability of relationships ousentability of redationships hyootheses.

3.1 swoport the

The instructor teaches the team how to do a finctional analysis of
adversany, basort on their tactics, capabilities types of targets

adversary, basort on their tactics, capabialites, types of targets,

example of how to tim that analysis into cointermeasins The

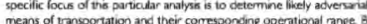

applying this range radilly to pnor attack sites, analysts can designese

rugh geogranical areas of interest that contain suspected acversan

Mixed - due to
some resistance

to overtion

the adverary's capabiling

dired action growe

instructor shows now to choose and employ approprate tools for disterig knos of partem delection and analysis of adversary activity. Specilically, stows how plotwhecel tool is wet-suited lor seceng pattens

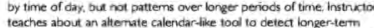

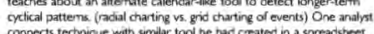
on an eartier deployment into an active theater. He had use the contextaal annotation leature of the spreacsheec, and a customized symbology, 10 dralyze longer-term acversary activity with rich

1 Team in not successfily builcing an operational firm the constraints in the word and

Instructor H says "you mast lock for decpe info, its not all going to be Mixedhow

do a functional analysis of an adversan, based on their tactics,

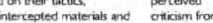

personnel. Then he grives an examole of how to tum that aralyisis int

contermeasures. The spectic foc.s of this paricuabr mathsis is 6

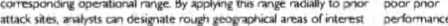

that contain susported adversarial direct action groups

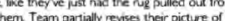
the acvesay

Tem partially revises ther peture of the adversay. construction of an inferertial model of the target doman (undertanding the sey structure).

153.1 Support the understanding of $e$

221 Support the detection and recognition of erents

2.212 Support

comainerevevant pattem

3.1 Support the
constriction of an inferential (understanding the key thenter).

Table 3.2: Process tracing tables for intervention 2 on day 2. 


\subsubsection{Intervention 3: Examining Physical Evidence and Ex- ploiting Intercepted Materials}

This intervention was meant as a broadening check regarding the level of detail the teams exercised when examining physical artifacts. Specific topics include: examining physical evidence and then exploiting the intercepted materials afterwards for intelligence value. 


\begin{tabular}{|c|c|c|c|c|c|}
\hline Team & Mindser/Context & Cues/interventions & Receptivity & ActionsiResponses & Mapping to Model \\
\hline & $\begin{array}{l}\text { Team prematurely } \\
\text { namowed in assessment } \\
\text { of recently intercepted } \\
\text { materials as not holding } \\
\text { significant meaning } \\
\text { Team is unaware that } \\
\text { the objects hold indirect } \\
\text { data. }\end{array}$ & $\begin{array}{l}\text { Instructor encourages more thorough } \\
\text { investigation of physical artifacts - for } \\
\text { instance considering how an object was } \\
\text { used by an adversary, in addition to } \\
\text { examining its physical attributes. }\end{array}$ & $\begin{array}{l}\text { High- due to } \\
\text { engagement } \\
\text { level in scenario }\end{array}$ & $\begin{array}{l}\text { Team examines items closer and finds } \\
\text { several usage marks, and hidden meaning/ } \\
\text { messages. They generates some new } \\
\text { hypotheses of possible uses for recovered } \\
\text { items, leading to more hypotheses about } \\
\text { adversary COAs. }\end{array}$ & $\begin{array}{l}1.3 \text { Support the } \\
\text { deternination of source } \\
\text { value (l.e, where to look). }\end{array}$ \\
\hline & $\begin{array}{l}\text { Team is considering } \\
\text { different ways how a } \\
\text { recovered object can } \\
\text { carry meaning } \\
\text { Brainstorming session } \\
\text { and hypothesis } \\
\text { oiscussion reveals an } \\
\text { attempt to avoid } \\
\text { premature closure on } \\
\text { one course. At same } \\
\text { time, they do condude } \\
\text { fairly quickly that } \\
\text { commandos must be } \\
\text { involved somehow. } \\
\text { question tums to how } \\
\text { to distinguish between } \\
\text { commandos acting in a } \\
\text { direct action fashion } \\
\text { versus acting along with } \\
\text { or in support of trained } \\
\text { locals. }\end{array}$ & $\begin{array}{l}\text { Instructor encourages more thomough } \\
\text { investigation of physical artifacts - for } \\
\text { instance considering how an object was } \\
\text { used by an adversary, in adidition to } \\
\text { examining its physical attributes. } \\
\text { Instructor pushes them to continue to } \\
\text { consider how to distinguish between } \mathrm{hl} \\
\text { (commandos as DA) and h2 } \\
\text { (commandos as training cadre for locals) }\end{array}$ & $\begin{array}{l}\text { Low/Mixed. } \\
\text { due to } \\
\text { resistance to } \\
\text { overtum current } \\
\text { mindset. }\end{array}$ & $\begin{array}{l}\text { Team identifies potential discriminatory } \\
\text { evidence between the two hypotheses. } \\
\text { weapons used is seen as key, almost to } \\
\text { the extent that it is viewed as the only } \\
\text { key piece of evidence } \\
\text { The team discusses the need for the } \\
\text { commancos to somehow communicate } \\
\text { with local groups (hyp. 2), but this isn't } \\
\text { focused on nearly as much on as the } \\
\text { weapons evidence is by the time of the } \\
\text { instructor intervention. Team has settled } \\
\text { on hypothesis of a single commando cell } \\
\text { and a single insurgent cell. Commando cell } \\
\text { operating in DA operations across the } \\
\text { countryside and occasionally linking up } \\
\text { with locals for joint ops. } \\
\text { Team is teetering on edge of premature } \\
\text { closure - they are hypothesis testing, but } \\
\text { have 'conchuded' already that there, are } 2 \\
\text { groups and are now just trying } \\
\text { discriminate two different ways these } \\
\text { groups might be acting -with commandos } \\
\text { as trainers or commandos primanily as DA } \\
\text { assets. }\end{array}$ & $\begin{array}{l}\text { 3.3.1 Support the } \\
\text { observability of the } \\
\text { hypothesis SET and how } \\
\text { they relate (compete or } \\
\text { comelate). } \\
\text { 3.5.I Support the } \\
\text { observability of relationships } \\
\text { between finuings and } \\
\text { hypotheses. } \\
\text { 3.2.1 Support the } \\
\text { observability of relationships } \\
\text { between interpretations and } \\
\text { hypotheses. } \\
\text { I Support the extraction of } \\
\text { essential, representative, 'on } \\
\text { analysis' smple from } \\
\text { available data. } \\
\text { 1.10 Support collection } \\
\text { 'outside the focus' (to } \\
\text { stimulate broadening). }\end{array}$ \\
\hline & $\begin{array}{l}\text { Team is trying to } \\
\text { uncover insight into } \\
\text { recovered items from } \\
\text { adversanal interaction. }\end{array}$ & $\begin{array}{l}\text { Instructor encourages more thorough } \\
\text { investigation of physical artifacts - for } \\
\text { instance considering how an object was } \\
\text { used by an adversary, in addition to } \\
\text { examining its physical attributes. } \\
\text { "don't just look at the map, examine it" } \\
\text { Instructor pushes team to consider how } \\
\text { the recovered tennis ball could be use to } \\
\text { pass messages. }\end{array}$ & $\begin{array}{l}\text { High-due to } \\
\text { engagement } \\
\text { level with } \\
\text { scenario. }\end{array}$ & $\begin{array}{l}\text { Team forms hypothesis that ternis balls } \\
\text { are used for dead crop message system. } \\
\text { Team generates new collection tasking } \\
\text { based on exploitation of the usage } \\
\text { artifacts left on the recovered map. } \\
\text { Team generates recommencation for } \\
\text { specific countermeasures based on one } \\
\text { interpretation of the message in the } \\
\text { tennis ball. } \\
\text { Team hypothesizes about reasons for the } \\
\text { ternis ball courier committing suicide. } \\
\text { Team sets up competing hypothesis } \\
\text { framework to compare evidence } \\
\text { supporting competing interpretations of } \\
\text { the recovered message. }\end{array}$ & $\begin{array}{l}\text { 1 Support the extraction of } \\
\text { essential, representative, 'on } \\
\text { analysis' sample from } \\
\text { available data. } \\
1.10 \text { Support collection } \\
\text { 'outside the focus' (to } \\
\text { stimulate broadening). } \\
2.6 \text { Support revised C \& C } \\
\text { efforts based on alternative } \\
\text { hypotheses and holes in the } \\
\text { hypothesis set. } \\
\text { 1.1.2 Support refocusing the } \\
\text { collection process based on } \\
\text { revised hypotheses. }\end{array}$ \\
\hline & $\begin{array}{l}\text { Team is trying to exploit } \\
\text { recovered map. }\end{array}$ & $\begin{array}{l}\text { Instructor points out interesting } \\
\text { characteristics, and encourages closer } \\
\text { examination. }\end{array}$ & $\begin{array}{l}\text { High-due to } \\
\text { engagement } \\
\text { level with } \\
\text { scenano. }\end{array}$ & $\begin{array}{l}\text { Team examines items closer and finds } \\
\text { several usage marks, and hypothesizes } \\
\text { about the reason for them being there. }\end{array}$ & $\begin{array}{l}\text { I Support the extraction of } \\
\text { essential, representative, 'on } \\
\text { analysis' sample from } \\
\text { available data. } \\
2 \text { Support the construction } \\
\text { of accurate interpretations } \\
\text { of the findings. }\end{array}$ \\
\hline
\end{tabular}

Table 3.3: Process tracing table for intervention 3 on day 2 afternoon. 


\subsubsection{Intervention 4: Surprise Briefing Demand by "Angry" Superior Officer}

This intervention was different than the others. The instructors had a guest officer play the part of an emotional, angry german colonel who has just learned his family was killed by the insurgents. He bursts into the workspace yelling, and demands an immediate assessment of insurgent sites to raid. The team is put in a precipitous situation under time and resource pressure, leading to a breakdown in synthesis from earlier assessments. Specifically, a common tactic of the insurgent attacks was to leave booby traps behind. The team did not provide this warning to the angry officer, and as a result his strike force suffered massive casualties at the raid site. The intervention portion of this interaction takes place as an after-action review, a few minutes after the team is forced to make a snap assessment. The instructor runs through the importance of always being able to brief, and to not get locked into production cycles, amongst other topics. 


\begin{tabular}{|c|c|c|c|c|c|}
\hline Team & MindsedContrext & Cuesilnterventions & Receptivicy & Actions/Responses & Mapping to Model \\
\hline & $\begin{array}{l}\text { Overwheimed with } \\
\text { emotionally charged } \\
\text { demand for immediate } \\
\text { actionable intelligence } \\
\text { from an angy senior } \\
\text { officer. Extreme time } \\
\text { pressure forces a rush } \\
\text { to make } \\
\text { recommendations of an } \\
\text { adversary target to hit. }\end{array}$ & $\begin{array}{l}\text { Senior officer comes in } \\
\text { clearty upset over } \\
\text { (fictionalized) loss of his } \\
\text { family members to } \\
\text { adversary action. Demands } \\
\text { immediate briefing from } \\
\text { analyst team's leader on } \\
\text { targets to hit. (This is a } \\
\text { planned measure to } \\
\text { increase the realism and } \\
\text { level of engagement of the } \\
\text { exercise.) }\end{array}$ & $\begin{array}{l}\text { High - due to } \\
\text { engagement } \\
\text { level of scenario } \\
\text { in emotionally } \\
\text { charged } \\
\text { situation. }\end{array}$ & $\begin{array}{l}\text { Team hastily recommends some sites to } \\
\text { strike, but doesn't pass along wamings about } \\
\text { possibility of booby traps (from earlier analysis } \\
\text { of adversary capabilities). This failure to } \\
\text { spnthesize previous analyses results in massive } \\
\text { casualties to the strike force. The angry } \\
\text { officer returns, and demotes the analyst } \\
\text { team's leader for the lack of waming } \\
\text { After some time, the senior officer and the } \\
\text { rest of the instructional cadre retum for an } \\
\text { after-action review (teachable moment). } \\
\text { They discuss the role of the rest of the team } \\
\text { in supporting the tearn's leader (cross- } \\
\text { checking for resilence), and the need to } \\
\text { synthesize and connect from previous } \\
\text { analyses. }\end{array}$ & $\begin{array}{l}\text { 1.5.4 Support the awareness of } \\
\text { down-collect history. (History in } \\
\text { current analysis vs. past analyses) } \\
\text { 1.6.1 Support the determination } \\
\text { of relevance of past analyses (e.g. } \\
\text { staleness, context) } \\
\text { 2.2.1.2 Support domain-relevant } \\
\text { pattern recognition in the data. } \\
\text { 3.1 Support the construction of } \\
\text { an inferential model of the target } \\
\text { domain (understanding the key } \\
\text { functions and organizational } \\
\text { structure). }\end{array}$ \\
\hline
\end{tabular}

2

\begin{tabular}{|c|c|}
\hline $\begin{array}{l}\text { Overwheimed with } \\
\text { emotionally charged } \\
\text { demand for immediate } \\
\text { actionable intelligence } \\
\text { from an angy senior } \\
\text { officer. Extreme time } \\
\text { pressure forces a rush } \\
\text { to make } \\
\text { recommendations of an } \\
\text { adversary target to hit. }\end{array}$ & $\begin{array}{l}\text { Senior officer comes in } \\
\text { clearty upset over } \\
\text { (fictionalized) loss of his } \\
\text { family members to } \\
\text { adversary action. Demands } \\
\text { immediate briefing from } \\
\text { analyst tearn's leader on } \\
\text { targets to hit. (This is a } \\
\text { planned measure to } \\
\text { increase the realism and } \\
\text { level of engagement of the } \\
\text { exercise.) }\end{array}$ \\
\hline
\end{tabular}

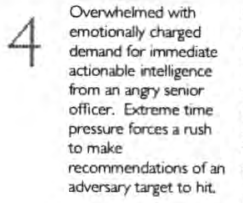

Senior officer comes in clearly upset over (fictionalized) loss of his family members to adversary action. Dernancs immediate briefing from analyst team's leader on targets to hit. (This is a

planned measure to level of ere realsm and level of engagement of the exercise)

High - due to
engagement
level of scenano
in emotionally
charged
situation.

eam hastily recommends sorre sites to strike, but doesn't pass along wamines about down-collect history. (History in possibility of booby traps (from earlier analysis cument analysis vs past analyses) of adversary capabilities). This failure to

synthesize previous analyses results in massive $\quad 1.6,1$ Support the determination casualies to the strike force. The angry of relevance of past analyses (eg. officer returns, and demotes the anats team's leader for the lack of waming.

After some time, the senior officer and the rest of the instructional cadre retum for after-action review (teachable moment). They discuss the role of the rest of the tean in supporting the tean's leader (crosschecking for resilicnce), and the need to symthesize and connect from previous analyses. staleness, contex:

2.2.1.2 Support domain-relevant pattem recognition in the data.

3.1 Support the construction of an inferential model of the target domain (understanding the key functions and organizationa structure)

Moxed/High - Team refuses to make unassessed

1.5.4 Support the awareness of due to recommendation and won't name any sites to down-collect history. (History in engagement strike, and also doesn't pass along wamings current analysis vz. past analyses) ievel of scenario the, and also doesn't pass along wamings

in emotionally analysis of adversary capabilities). Angry 1.6.1 Support the determination charged officer sends strike force anyways. The fallune of relevance of past analyses (eg. situation. Team to synthesize previous analyses results in staleness, context doesn't respond massive casualties to the strike force. The within window, angry officer retums, and demotes the analyst 2.2.1.2 Support domain-relevant tean's leader for the lack of warning. pattem recognition in the data. consequences still occur as After some time, the senior officer and the response.

rest of the inste, the senior oficer and the rest of the instructional cadre return for
after-action review (teachable moment). They discuss the role of the rest of the team in supporting the tearn's leader (cross. checking for resilience), and the need to synthesize and connect from previous

3.1 Support the construction of an inferential model of the target domain (understanding the key functions and organizationa structure). analyses.

Table 3.4: Process tracing table for intervention 4 on day 2 afternoon. 


\subsubsection{Intervention 7: Exploitation of Recovered Cache Items}

This intervention deals with the exploitation of recovered insurgent cache items, specifically as a way to understand the normal operating procedures and constraints of the adversary. 
Ithtervention 7: (day 3 midder) Exploistion of Recovered Cache item

\begin{tabular}{|c|c|c|c|c|c|}
\hline ean & Mindsed Contest & Cuestritervencions & Recepevity & ActionsiResponses & Mapp pa to Mocel \\
\hline & 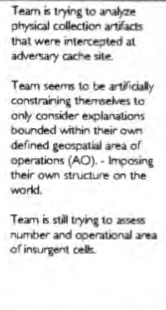 & 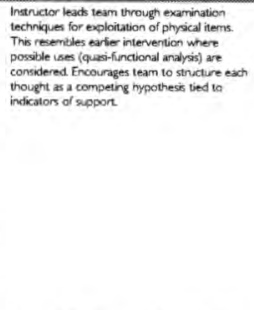 & $\begin{array}{l}\text { Lowimbioed: } \\
\text { team doesn't } \\
\text { seem to grasp } \\
\text { competing } \\
\text { hypothesis } \\
\text { concept }\end{array}$ & 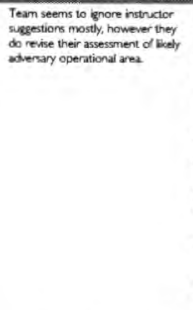 & 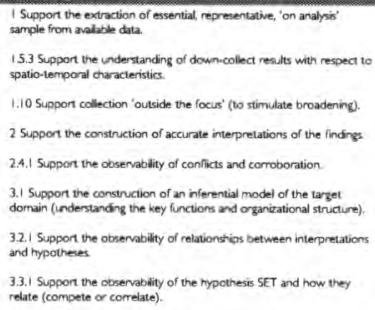 \\
\hline & 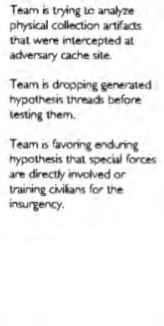 & 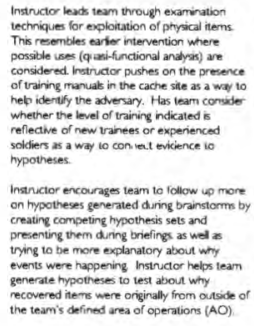 & $\begin{array}{l}\text { High- teart } \\
\text { begins to } \\
\text { integrate. } \\
\text { symthesize, and } \\
\text { test from nartier } \\
\text { assessments as } \\
\text { tausht in } \\
\text { intevention. }\end{array}$ & 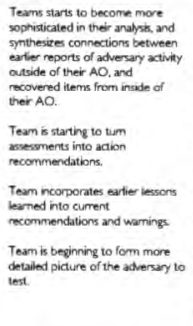 & 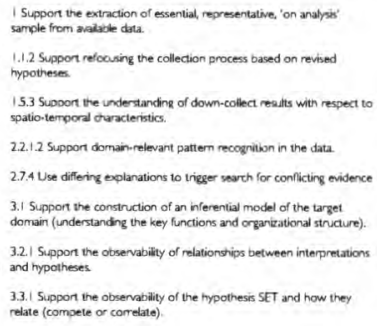 \\
\hline 6 & 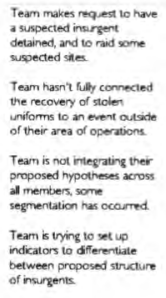 & 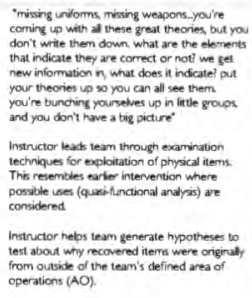 & $\begin{array}{l}\text { High- tearn } \\
\text { begins to } \\
\text { integrate. } \\
\text { smatesize, and } \\
\text { test from cartier } \\
\text { assessments as } \\
\text { tuaght in } \\
\text { intervention }\end{array}$ & 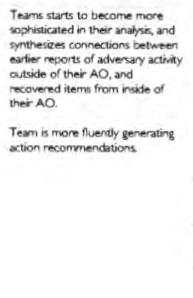 & 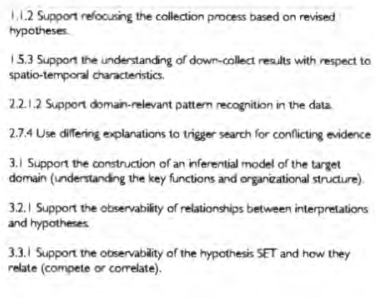 \\
\hline 1 & 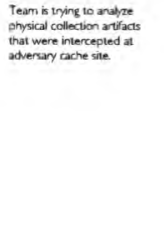 & 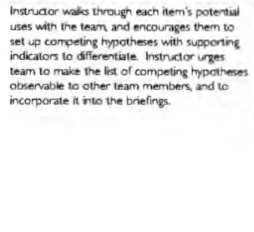 & $\begin{array}{l}\text { Higgr- leam } \\
\text { begins to } \\
\text { integrate, } \\
\text { synthesize, and } \\
\text { test from earier } \\
\text { assessments as } \\
\text { taughti in. } \\
\text { intervertion }\end{array}$ & 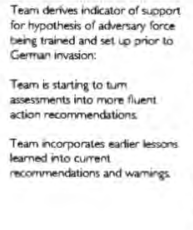 & 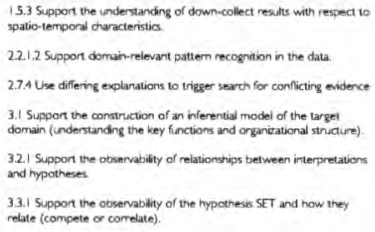 \\
\hline
\end{tabular}

Table 3.5: Process tracing table for intervention 7 on day 3 midday. 


\subsubsection{Intervention 11: Functional Analysis of Adversary Modus Operandi}

This intervention deals with a tactic for discerning the operational range of a specific insurgent cell based on human limitations and tracing back constraints in the world. Specifically, using a calculated range based on walking speed, and an attack window based on periods of low illumination at night, the instructors showed the teams how to map out potential safehouses, cache sites, and target sets for the adversary. 


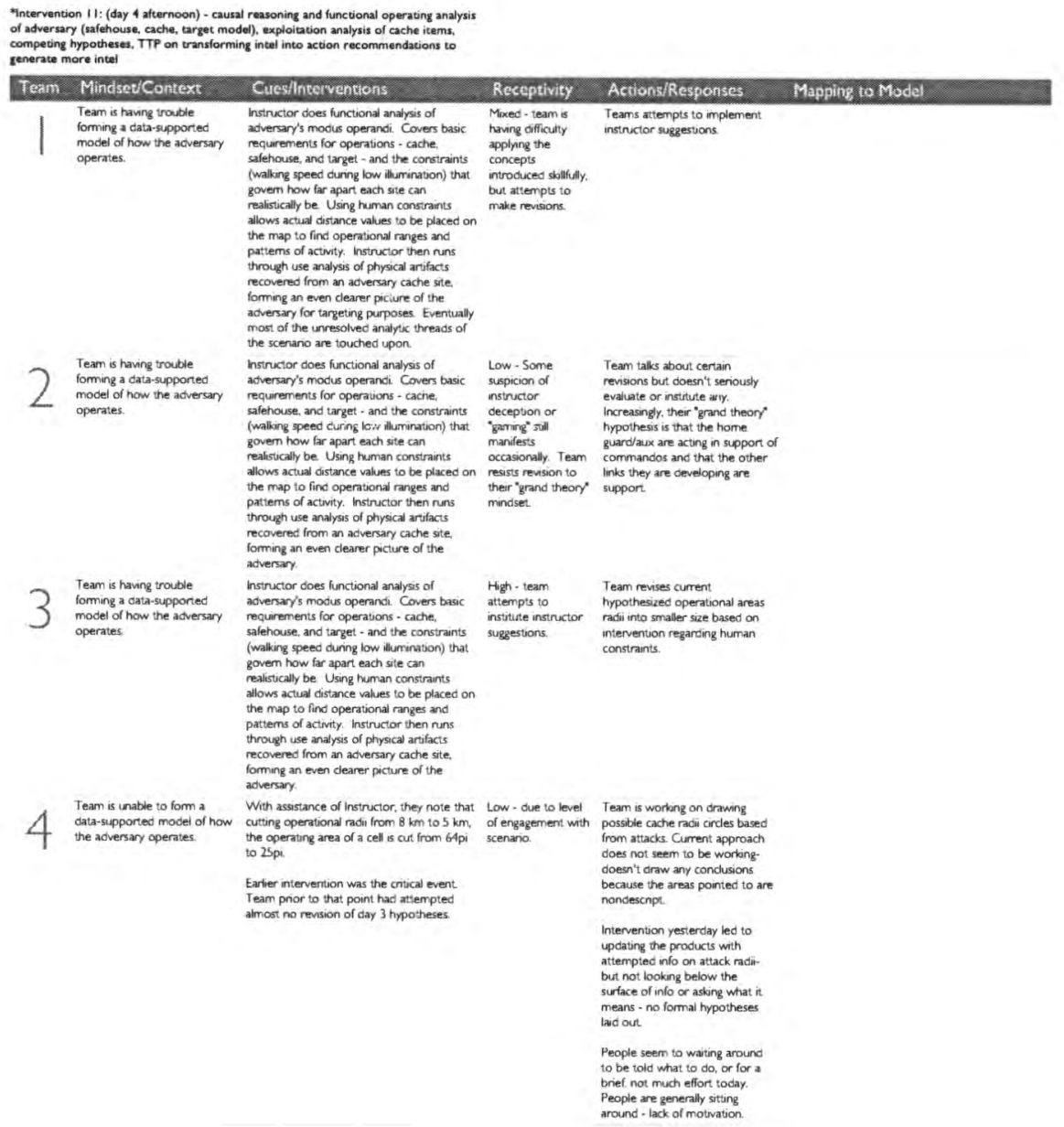

Table 3.6: Process tracing table for intervention 11 on day 4 afternoon. 


\subsubsection{Intervention 13: Stolen Torpedo Hypothesis Brainstorm- ing and $\mathrm{ACH}$ Methodology}

This intervention dealt with several methods for doing hypothesis exploration, specifically brainstorming and analysis by competing hypotheses. The object of the intervention was to use a teachable moment to show the team how to figure out possibilities for the use and transport of a stolen torpedo warhead. 

Mntervention 13: (day 5 moming) Torpedo Hypothesis/Brainstorming/ACH
Methodology

\begin{tabular}{|c|c|c|c|c|c|}
\hline $\mathrm{ar}$ & Mindset Context: & Cuesilnterventions & Receptivity & ActionsiResponses & Mapping to Model \\
\hline & $\begin{array}{l}\text { Team is working a number of } \\
\text { disparate trreads. }\end{array}$ & $\begin{array}{l}\text { No significant intervention - instructor } \\
\text { encourages them to brainstorm to } \\
\text { generate multiple competing hypotheses } \\
\text { about how the adversary will use the } \\
\text { torpedo they seized. }\end{array}$ & $\begin{array}{l}\text { Moxed - tearn is } \\
\text { busy and doesn't } \\
\text { want the } \\
\text { interruption } \\
\text { affecting workllow. }\end{array}$ & No drta & $\begin{array}{l}3.3 \text { Support the generation and exploration } \\
\text { of alternative hypotheses } \\
\text { 3.3.1 Support the observability of the } \\
\text { hypothesis SET and how they relate } \\
\text { (compete or correlate) }\end{array}$ \\
\hline & $\begin{array}{l}\text { Team displays periodic } \\
\text { manifestations of distrust of } \\
\text { the instructors' guidance- } \\
\text { team thinks they are being led } \\
\text { astray. } \\
\text { Team is trying to hypothesize } \\
\text { uses for the torpedo. } \\
\text { Team tends to accept } \\
\text { hyputheses unce they } \\
\text { generate them, rather than } \\
\text { testing them nigorously. }\end{array}$ & 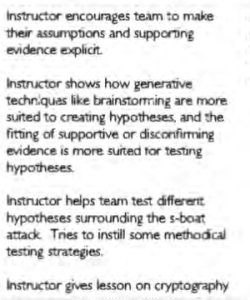 & $\begin{array}{l}\text { Low - team } \\
\text { periodically thinks } \\
\text { instructor is } \\
\text { "gaming them to } \\
\text { lesd them astray. }\end{array}$ & $\begin{array}{l}\text { Team intially doesn't pursue } \\
\text { hypothesis testing very vigorousty, bur } \\
\text { begins to attempt to stucture } \\
\text { competing hypotheses to figure out } \\
\text { most likely use for the stolen torpeda. }\end{array}$ & $\begin{array}{l}35 \text { Support the generation of altemative } \\
\text { hypotheses from new findings. (broadening) } \\
\text { 3.3.1 Support the observability of the } \\
\text { hypothesis SET and how they relate } \\
\text { (compete or carrelate) } \\
\text { 3.3 Support the generation and exploration } \\
\text { of aternative nypotneses } \\
3.21 \text { Support the observabifity of } \\
\text { relationships between interpretations and } \\
\text { hypotheses. } \\
27.4 \text { Use differing explanations to trigger } \\
\text { seanch for conflicting evidence }\end{array}$ \\
\hline & $\begin{array}{l}\text { Team is preparing for } \\
\text { individual brieft, getring } \\
\text { everyone on the same } \\
\text { common ground } \\
\text { understanding of the group } \\
\text { assessment. } \\
\text { Team is tring to figure ort } \\
\text { how the stolen toppedo was } \\
\text { transported and its intended } \\
\text { use. }\end{array}$ & $\begin{array}{l}\text { Instructor in encouraging brainstorming } \\
\text { as a way to generate enermy } \mathrm{COAs} \text { and } \\
\text { competing hypotheses. Instructor } \\
\text { begins by tracing backwards how } \\
\text { insurgents could move the torpedo. } \\
\text { using a perspective grounded in the } \\
\text { operational constraints of the adversary. }\end{array}$ & $\begin{array}{l}\text { High - tearn grasps } \\
\text { use of technique } \\
\text { being instructed }\end{array}$ & $\begin{array}{l}\text { Team generates several hypotheses } \\
\text { for the movernent of the torpedo, } \\
\text { and the instructor helps them } \\
\text { disconfirm most of them by reasoning } \\
\text { through the constraints. At the end of } \\
\text { the intervention they instructor tries } \\
\text { to lead them to the conclusion that } \\
\text { they should arest a particular } \\
\text { insurgent, but the team had aready } \\
\text { requested that person be detained } \\
\text { earlier. }\end{array}$ & $\begin{array}{l}3.21 \text { support the observability of } \\
\text { relationships besween interpretations and } \\
\text { hypotheses. } \\
3.3 \text { Support the generation and exploration } \\
\text { of alternative hypotheses } \\
3.51 \text { Support the observablity of } \\
\text { relationships between findings and } \\
\text { hypotheses. } \\
1.13 \text { Support refocusing the selection } \\
\text { process based on revised hypotheses. }\end{array}$ \\
\hline & $\begin{array}{l}\text { Team is trying to figure out } \\
\text { the adversary's intert with the } \\
\text { stolen torpedo. }\end{array}$ & 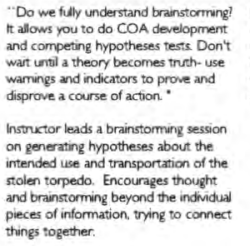 & $\begin{array}{l}\text { Low - engagenent } \\
\text { level with the } \\
\text { sceranio is down. } \\
\text { team doesn't } \\
\text { rigorousty pursue } \\
\text { analyic threads. }\end{array}$ & $\begin{array}{l}\text { Team doesn't seem to internalize } \\
\text { much at this point, there seems to be } \\
\text { some engagement problems. The only } \\
\text { part of the intervention yesterday that } \\
\text { they took to heart is updating the } \\
\text { products with attempted info on } \\
\text { adversary's operational area - they are } \\
\text { sill not looking below the surface of } \\
\text { information or asking what it means } \\
\text { when deriving enemy MO or } \\
\text { interntions - no formal hypotheses } \\
\text { have been laid ois and tested. }\end{array}$ & $\begin{array}{l}3.21 \text { Support the observability of } \\
\text { relationships between interpretations and } \\
\text { hypotheses. } \\
3.3 \text { Support the generation and exploration } \\
\text { of aternative hypotheses. } \\
35.1 \text { Support the observability of } \\
\text { relationships between findings and } \\
\text { hypotheses. } \\
1.1 .3 \text { Support refocusing the selertion } \\
\text { process based on resised hypotheses }\end{array}$ \\
\hline
\end{tabular}

Table 3.7: Process tracing table for intervention 13 on day 5 morning. 


\subsubsection{Intervention 14: Cryptography Lesson, Exploiting Crypto and ELINT}

This intervention was more technical in nature, cover topics dealing with basic cryptograph and electronic intelligence intercepts (ELINT). The focus was on teaching one way to encode or decode a secret message, and then once the message was decoded, how to exploit it for intelligence value. 


\begin{tabular}{|c|c|c|c|c|c|}
\hline Team & Mindsev'Context & Cucsilnterventions & Receptivity & AcrionstResponses & Mapping to Model \\
\hline & $\begin{array}{l}\text { Team is having difficulty } \\
\text { decrypting intercepted } \\
\text { message, and is firustrated that } \\
\text { their formal RF/s aren't } \\
\text { producing any information or } \\
\text { results (requess for } \\
\text { information - simulared } \\
\text { interactivity with nest of } \\
\text { miltary) }\end{array}$ & 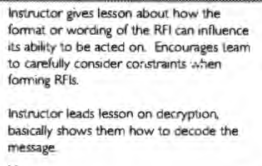 & $\begin{array}{l}\text { Low- due to level } \\
\text { of engagement with } \\
\text { scenano, dificuty } \\
\text { of task and lack of } \\
\text { desired interactivity. }\end{array}$ & $\begin{array}{l}\text { Team is losing engagement with } \\
\text { the exercise } \\
\text { Team decodes message, but only } \\
\text { with very explict help. }\end{array}$ & $\begin{array}{l}\text { 1.1.2 Support refocusing the collection process } \\
\text { based on revised hypotheses } \\
\text { 1.1.2.2 Support refocusing the collection frocess } \\
\text { based on new interpretations. }\end{array}$ \\
\hline & $\mathrm{x}$ & $x$ & $x$ & $x$ & $x$ \\
\hline & $\begin{array}{l}\text { Team is having dificulty } \\
\text { decrypting iniercepted } \\
\text { message. }\end{array}$ & 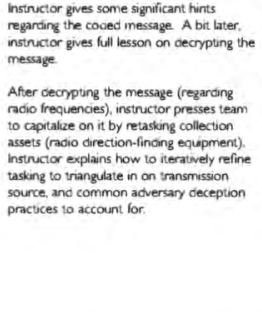 & $\begin{array}{l}\text { High- team was } \\
\text { hwving srouble with } \\
\text { task difficuly level. } \\
\text { bul after } \\
\text { intervention moved } \\
\text { quicky into } \\
\text { sminthesis and } \\
\text { recommendations. }\end{array}$ & $\begin{array}{l}\text { Team decrypts message after } \\
\text { hints, and mmediately forms a } \\
\text { most tikely hypothesis regarding } \\
\text { its neaning The decoded } \\
\text { message is excernalized in a } \\
\text { sharable way. } \\
\text { Team isn't able to imminediately } \\
\text { exploit message meaning but } \\
\text { begins process of locating } \\
\text { potential racio transmission sites } \\
\text { to investigate. }\end{array}$ & 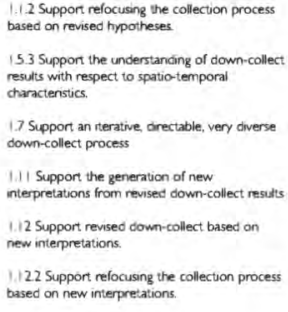 \\
\hline & $\begin{array}{l}\text { Team has reached an impasse } \\
\text { inning to decocele the } \\
\text { intercepted message }\end{array}$ & 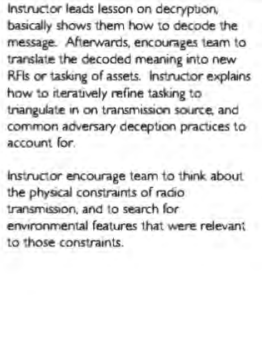 & $\begin{array}{l}\text { High - team } \\
\text { attempts to } \\
\text { sinthesize with } \\
\text { instructor } \\
\text { assistance. }\end{array}$ & 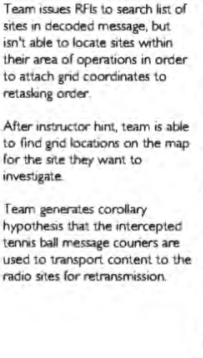 & 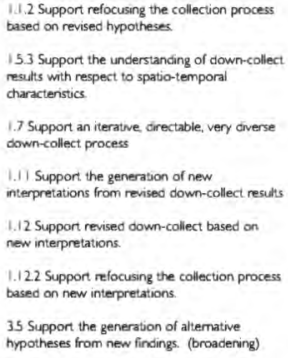 \\
\hline
\end{tabular}

Table 3.8: Process tracing table for intervention 14 on day 5 midday. 


\subsection{Analyst Team Receptivity to Instructor Interventions}

The role of instructor interventions as a broadening check against premature narrowing bore mixed results with respect to the team analytic process. On one hand, the instructors had designed the scenario purposefully with embedded hazards for the analytic teams to fall prey to. Teams were placed into precipitous situations under time and resources pressures while forced to make recommendations or assessments. The intent of this was to force mistakes, then draw upon the experience of the instructors and intervene in the analytic process to teach against a particular vulnerability. Overall, this shaping gave an excellent view into what expert practitioners felt were common or particularly vexing analytic vulnerabilities of the domain.

However, teams were not always responsive to these interventions, and in some cases perceived them as even intended to deceive them into choosing an incorrect course of action, or as part of the "fog of war" in the scenario.

In their final evaluations, two of the four teams were given a passing grade, and two a failing grade, who then had to redo their final briefing until it was satisfactory. Interestingly, the two failing teams corresponded most often with the least receptive or revisionary behavior in the protocol analysis relative to instructor interventions.

Further work needs to be done to explore this relationship between broadening checks and stronger analytic process. We feel, however, that this data offers additional support for the idea that broadening checks are a critical component of process resilience, as suggested in earlier findings in this area (Zelik et al., 2007). 


$\begin{array}{cllll}\text { receptivity: } & \text { team } & \text { team2 } & \text { team } 3 & \text { team 4 } \\ \text { intervention 1 } & \text { high } & \text { mixed } & \text { high } & \text { n/a } \\ \text { intervention 2 } & \text { low } & \text { mixed } & \text { mixed } & \text { mixed/low } \\ \text { intervention 3 } & \text { high } & \text { low/mixed } & \text { high } & \text { high } \\ \text { intervention 4 } & \text { high } & \text { n/a } & \text { high } & \text { mixed/high } \\ \text { intervention 7 } & \text { low/mixed } & \text { high } & \text { high } & \text { high } \\ \text { intervention 11 } & \text { mixed } & \text { low } & \text { high } & \text { low } \\ \text { intervention 13 } & \text { mixed } & \text { low } & \text { high } & \text { low } \\ \text { intervention 14 } & \text { low } & \text { n/a } & \text { high } & \text { high } \\ & & & & \text { pass }\end{array}$

Table 3.9: Summary table of analytic team receptivity to instructor interventions. 


\section{CHAPTER 4}

\section{DISCUSSION}

When mapped from the process tracing onto the support function network, the instructor interventions tended to cluster around the "Hypothesis Exploration" area. This exercise employed a low-tech scenario and analytic operating environment for the purpose of focusing on core analytic technique instead of learning (tech-based) support tools. This helped simplify observations, and made the training goals of the exercise more apparent. From earlier work, a survey of analytic visualization tools were evaluated for support and mapped to the support function network. In that case, most of the tools tended to map onto the down collect area of support functions. This suggests a disconnect between what the instructors desire the analysts to learn and employ, and what support tools are available to them in deployment.

\subsection{Scenario Design}

Because it was a low tech scenario, issues like data overload weren't as prevalent. This could also have some effect on the minimization of down collect support functions by the instructors.

The three roles of the instructors were not uniformly performed (instruct, command, administer) throughout the scenario. Typically, the instruct and admin roles 


\section{Finding the Decision Support}

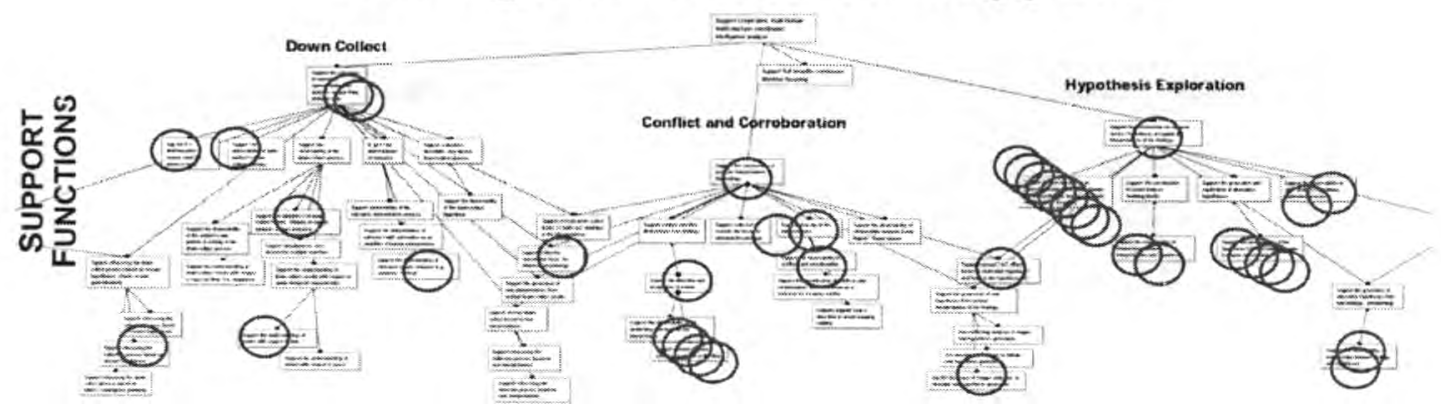

Figure 4.1: A version of the Support Function Model with Instructor Interventions mapped to it.

were played with a much lower quality or fidelity. In addition, there were some variations between instructors in the instruct role. Particularly, some instructors lead the teams by the nose, while others had more tolerance for divergence and let the teams make mistakes.

\subsection{Role of Broadening Checks}

One potential application of this research would be to teach junior analysts the techniques of doing/teaching broadening checks, especially if they are going to be leading their own analytic shops. Being able to recognize and facilitate broadening checks would be one way for them to instill more resilience in their analytic team.

In many cases, interventions made the teams back up or completely drop their current work thread, possibly to the detriment of continuity. In practice, or instantiated in a support tool, knowing how to balance a broadening function with maintaining continuity would be a very valuable line of future research. 


\subsection{Synthesis of Findings}

A general analytical finding was that teams displayed a consistent vulnerability of only perceiving meaning in textual information, instead of examining the full physical properties of intercepted artifacts. Similarly, teams also displayed a vulnerability in all-source intelligence by tending to analyze only direct information instead of the attributes of information medium. 


\section{REFERENCES}

Bodnar, J. (2003). Warning analysis for the information age: Rethinking the intelligence process. Bolling AFB, MD: Joint Military Intelligence College, Center for Strategic Intelligence Research.

Chalmers, B., Easter, J., \& Potter, S. (2000). Decision-Centred Visualisations for Tactical Decision Support on a Modern Frigate. Proceedings of 2000 Command and Control Research and Technology Symposium, Making Information Superiority Happen, 26-28.

Cook, R., Render, M., \& Woods, D. (2000). Gaps in the continuity of care and patient safety. BMJ, 320, 791-794.

Cook, R., Woods, D., Walters, M., \& Christoffersen, K. (1996). Coping with the complexity of aeromedical evacuation planning: Implications for the development of decision support systems. Proceedings of the $3 \mathrm{rdAnnual} \mathrm{Symposium}$ on Human Interaction with Complex Systems.

Elm, W., Potter, S., Tittle, J., Woods, D., Grossinan, J., \& Patterson, E. (2005). Finding decision support requirements for effective intelligence analysis tools. PROCEEDINGS OF THE HUMAN FACTORS AND ERGONOMICS SOCIETY 49TH ANNUAL MEETING.

Hollnagel, E., Mancini, G., \& Woods, D. D. (1988). Cognitive engineering in complex dynamic worlds. San Diego: Acadenic Press.

Hollnagel, E., Woods, D. D., \& Leveson, N. (2006). Resilience engineering: Concepts and precepts. Burlington, VT: Ashgate.

Hutchins, E. (1995a). Cognition in the wild. Cambridge, MA: MIT Press.

Hutchins, E. (1995b). How a cockpit remembers its speeds. Cognitive Science, 19(3), 265-288.

Miller, J., Patterson, E., \& Woods, D. (2001a). Critiquing as a cognitive task analysis (cta) methodology. PROCEEDINGS OF THE HUMAN FACTORS AND ERGONOMICS SOCIETY ANNUAL MEETING, 1, 518-522. 
Miller, J., Patterson, E., \& Woods, D. (2001b). Modeling expertise in a domain with diversity. Proceedings of the Human Factors and Ergonomics Society 45th annual meeting, 8-12.

Miller, J., Patterson, E., \& Woods, D. (2006). Elicitation by critiquing as a cognitive task analysis methodology. Cognition, Technology $\mathcal{E}$ Work, 8(2), 90-102.

Patterson, E., Roth, E., \& Woods, D. (2001). Predicting vulnerabilities in computersupported inferential analysis under data overload. Cognition, Technology and Work, 3(4), 224-237.

Patterson, E., Woods, D., Cook, R., \& Render, M. (2005). Collaborative crosschecking to enhance resilience. PROCEEDINGS of the HUMAN FACTORS AND ERGONOMICS SOCIETY 49th ANNUAL MEETING.

Potter, S., Ball, R., \& Elm, W. (1996). Supporting aeromedical evacuation planning through informationvisualization. Human Interaction with Complex Systems, 1996. HICS'96. Proceedings., Third Annual Symposium on, 208-215.

Potter, S., Elm, W., Roth, E., Gualtieri, J., \& Easter, J. (2002). Bridging the gap between cognitive analysis and effective decision aiding. State of the Art Report (SOAR) - Cognitive Systems Engineering in Military Aviation Environments: Avoiding Cogminutia Fragmentosa, 137-168.

Potter, S., McKee, J., \& Elm, W. (1997). Decision centered visualization for the military capability spectrum project. Unpublished technical report). Pittsburgh, PA: Carnegie Group.

Potter, S., Roth, E., Woods, D., \& Elm, W. (2000). Bootstrapping multiple converging cognitive task analysis techniques for system design. Cognitive Task Analysis, 317-340.

Roth, E., Lin, L., Kerch, S., Kenney, S., \& Sugibayashi, N. (2001). Designing a firstof-a kind group view display for team decision making: a case study. Linking Expertise and Naturalistic Decision Making. Lawrence Erlbaum Associates, Inc, Mahwah, NJ, 113-135.

Roth, E., Malsch, N., Multer, J., Coplen, M., Eng, R., \& Brookline, M. (1998). Analyzing railroad dispatchers' strategies: a cognitive taskanalysis of a distributed team planning task. Systems, Man, and Cybernetics, 1998. 1998 IEEE International Conference on, 3.

Trent, S. A. (2005). A study of the cognitive challenges and vulnerabilities of intelligence analysis. Unpublished master's thesis, The Ohio State University. (O: 
Thesis (M.S.)-Ohio State University, 2005; O: Includes bibliographical references (leaves 56-60); O:)

Vicente, K. (1999). Cognitive Work Analysis: Toward Safe, Productive, and Healthey Computer-Based Work. Norwood, NJ: Lawrence Erlbaum Associates.

Woods, D. (2003). Handbook of cognitive task design. In E. Hollnagel (Ed.), Handbook of cognitive task design (chap. Discovering how distributed cognitive systems work). Mahwah, N.J: Lawrence Erlbaum Publishers.

Woods, D. D. (1993). Process tracing methods for the study of cognition outside of the experimental psychology laboratory. Decision making in action: Models and methods. Norwood, NJ: Ablex, 228, 251.

Woods, D. D. (1994). Cognitive demands and activities in dynamic fault management: Abduction and disturbance management. In N. Stanton (Ed.), Human factors in alarm design (p. 63-92). London and Bristol, PA: Taylor and Francis.

Woods, D. D. (2003). Discovering how distributed cognitive systems work. Handbook of cognitive task design, 37-53.

Woods, D. D., \& Hollnagel, E. (2006). Joint cognitive systems: Patterns in cognitive systems engineering. Boca Raton, FL: CRC, Taylor \& Francis.

Woods, D. D., Johannesen, L., \& Cook, R. (1994). Behind human error: Cognitive systems, computers, and hindsight. Dayton, OH: CSERIAC, WPAFB.

Woods, D. D., O'Brien, J., \& Hanes, L. (1987). Human factors challenges in process control: The case of nuclear power plants. Handbook of human factors, 17241770 .

Woods, D. D., Patterson, E., \& Roth, E. (2002). Can we ever escape from data overload? a cognitive systems diagnosis. Cognition, Technology \& Work, 4(1).

Zelik, D., Patterson, E., \& Woods, D. D. (2007). Understanding rigor in information analysis. 8th International Conference on Naturalistic Decision Making. 